December 2004

\title{
How Important is the New Goods Margin in International Trade?
}

\author{
Timothy J. Kehoe \\ University of Minnesota \\ Federal Reserve Bank of Minneapolis
}

\author{
Kim J. Ruhl \\ University of Texas at Austin
}

\begin{abstract}
We examine the bilateral trade patterns of countries involved in significant trade liberalizations using detailed data on the value of trade flows by commodity. We find a striking relationship between a good's pre-liberalization share in trade and its growth subsequent to liberalization. The goods that were traded the least before the liberalization account for a disproportionate share in trade following the reduction of trade barriers. The set of goods that accounted for only 10 percent of trade before the liberalization may account for as much as 40 percent of trade following the liberalization. This new finding cannot be accounted for by the standard models of trade, which rely on increases in previously traded goods to produce trade growth. We modify the standard DornbuschFischer-Samuelson model of Ricardian trade to provide a model capable of delivering these new facts. Our specification improves on previous Ricardian models by providing a technology process that can be calibrated using data on intra-industry trade.
\end{abstract}

*C 2004, Timothy J. Kehoe and Kim J. Ruhl. We would like to thank Tom Holmes, Sam Kortum, Ed Prescott, James Schmitz, Kei-Mu Yi and participants at the IO-Trade and Macro workshops for many valuable comments. The views expressed herein are those of the authors and not necessarily those of the Federal Reserve Bank of Minneapolis or the Federal Reserve System. 


\section{Introduction}

The real value of trade between two countries can grow in only two ways. The countries can export more of the goods they had already been trading, which we define as growth on the intensive margin, or the countries can begin exporting goods they had not been previously trading, which we define as growth on the extensive margin. In the bulk of applied international trade models, growth in trade following a reduction in tariffs is driven by increases in the trade on the intensive margin. The factor-proportions models, as well as those employing imperfect competition, rely heavily on fixed trade patterns. ${ }^{1}$ Few models of international trade have incorporated an extensive margin, in which goods that were not previously traded could become traded following a decrease in trade barriers.

In this paper we study the detailed trade statistics of 6 different countries during significant trade liberalizations to determine the presence and importance of the extensive margin for trade growth. Our study spans all of North America and most of Europe, and includes such large-scale trade liberalizations as the North American Free Trade Agreement, the Canada-U.S. Free Trade Agreement (CAUSFTA) and the accessions of Greece, Spain and Portugal to the European Economic Community. We construct a new measure of the extensive margin that takes into account the relative importance of a good in a county's trade, rather than imposing fixed dollar value cutoffs for determining whether a good is traded or not.

We find significant evidence of growth in the extensive margin following a decrease in trade barriers. The set of least traded goods which accounted for only 10 percent of trade before the trade liberalization may grow to account for as much as 50 percent of trade following the liberalization. We find extensive margin growth for almost all of the country pairs we examine. Furthermore, we construct a time series measure and find that the growth in the extensive margin coincides with the timing of the trade liberalization, supporting our hypothesis that the extensive margin growth is driven by the trade liberalization and is not the consequence of other factors, such as the product cycle. In contrast, when we examine the extensive margin for the United States and trade partners with which there has been no major trade policy changes, we find little evidence of growth on the extensive margin. This

\footnotetext{
1 The same holds true for International Real Business Cycle models, models that exploit the Armington aggregator and others that feature trade in a composite good.
} 
suggests that extensive margin growth is brought about by changes in trade policy and changes little in response to events like business cycles.

The method we develop for measuring the extensive margin represents a substantial break from the few previous studies of the extensive margin. These other studies use fixed dollar value cutoffs to determine whether a good is traded or not in a particular period. Hummels and Klenow (2004) classify a good as not traded if the value of trade is 0 , while Evenett and Venables (2002) classify a good as not traded if its yearly value of trade is 50,000 1985 U.S. Dollars or less, regardless of the country in question. A 50,000 Dollar cutoff implies that a good trading for 0.03709 percent or less of Nepal's total trade is not considered traded, while a good trading for anything more than 0.00018 percent of total trade in China is counted as traded. ${ }^{2}$ In our measure of tradedness, we allow the actual dollar value cutoff to differ across countries, relying instead on the relative importance of these goods in a country's trade.

Evenett and Venables (2002) considers the extensive margin while studying the geographic distribution of exports in developing countries. They find that a significant fraction of a developing country's trade growth can be attributed to exports of "long standing exportables" to new destinations. Thus, their concept of the extensive margin is a cross-country aggregation of our bilateral concept. While they study a country's exports to many partners at two different points in time, we concentrate on single country pairs and construct a measure that allows us to study the extensive margin across all the years in our sample.

Hummels and Klenow (2004) uses detailed trade data to decompose a nation's trade into an extensive component and an intensive component for a large cross-section of countries. They find that the extensive margin is important in explaining why big countries trade more than small countries, in that, big countries trade more kinds of goods than smaller countries. Hillberry and McDaniel (2002) uses the Hummels and Klenow decomposition to study the growth in trade between the United States and its NAFTA partners. They find growth in both the intensive and extensive margins. We extend the decomposition in Hummels and Klenow (2004), in a way similar to that in Hillberry and

\footnotetext{
${ }^{2}$ China’s 1985 value of total trade was $\$ 27$ billion, while Nepal’s was only \$134 million.
} 
McDaniel (2002), to create a time series analog that is comparable to our measure of the extensive margin.

Following the methodology laid out here, Mukerji (2004) studies the liberalization of trade in India in the 1990s. Growth in the extensive margin is found in both Indian exports and imports. Sandrey and van Seventer (2004) also use the methodology developed here to study the liberalization of trade brought about by the Closer Economic Relationship between Australia and New Zealand starting in 1988. They find evidence that the extensive margin was growing for New Zealand exports to Australia during this period while the export share of these goods from New Zealand to the rest of the world was relatively stable. Their results in this respect are similar to ours in that extensive margin growth seems to coincide with trade liberalization.

The few models developed to incorporate the extensive margin have generally fallen into two classes. The first class of models features heterogeneous firms who produce differentiated products, who must pay a fixed cost in order to export and whose exports are subject to a trade barrier, usually a tariff, as in Melitz (2003), Alessandria and Choi (2003) and Ruhl (2003). The firms are heterogeneous in their productivity; low productivity firms could not make enough profits from exporting to cover the fixed cost, so they do not export; high productivity firms can generate enough export profits to cover the fixed cost, so they do export. These firms that do not export are producing nontraded goods. As trade barriers fall, the potential profits of nonexporting firms increase and, for some firms, these profits increase enough to cover the fixed export cost, inducing these firms to begin exporting. The firms that switch from not exporting to exporting are creating extensive margin growth in response to the change in trade barriers.

The second class of models are built around Ricardian models with many goods, as in Dornbusch, Fischer and Samuelson (1977). In these models each country can produce any good in the product space, but the counties have different productivities in the production of each good. Since the same good can be produced in either country, in the absence of trade barriers, a good is either produced in one country or the other and exported. When there are trade barriers, there will be goods that neither country can produce at a cost low enough to export, so both countries produce the nontraded good for domestic consumption. As trade barriers fall in these models, it becomes possible for some of these goods to be produced at a low enough cost in one country so that, given the lower 
tariff, it is optimal to produce the good in only one country and export it. These goods which go from being nontraded, and produced in each country, to being traded, and produced in only one country, show up as extensive margin growth in response to a decrease in trade barriers.

In this paper we provide a simple model that can produce growth in both the extensive and intensive margins. We do so by modifying a standard Ricardian model with a continuum of goods, as in Dornbusch et al. (1977), by relaxing the ordering of goods in the product space. Rather than impose an ordering based on productivity, we order the goods according to their Standard International Trade Classification (SITC) number. This ordering has two advantages. First, the SITC ordering is constructed to group similar items together, which is a characteristic we will exploit in our specification of technology. Second, an SITC aggregate (such as a 4-digit subgroup) is simply a closed interval in our product space, so it is conceptually straightforward to map our results back to the data. A country's productivity in producing a particular good is random. This specification yields both intra-industry trade and growth in the extensive margin in a model that can be calibrated. Intensive margin growth is driven by the combination of constant elasticity of substitution preferences and an elasticity greater than one.

Besides being able to produce the extensive margin, the model we present is also easily calibrated using readily available data. Recent attempts at calibrating Ricardian style models include Yi (2003), who uses the idea of revealed comparative advantage and Kraay and Ventura (2002), who use data on wages and education to calibrate the distribution of relative productivities . Eaton and Kortum (2002) and Bernard, Eaton, Jensen and Kortum (2003) use data on the pattern of world to trade to calibrate a multicountry Ricardian model of world trade. In that we also assume a distribution over relative productivities, and use data on trade patterns, our approach is similar to that of Eaton and Kortum (2002).

Section 2 defines the measures we will use to study new good trade. Section 3 presents the evidence on the extent of trade in new goods following 5 trade liberalizations and section 4 compares our measure to others found in the literature. In section 5 we modify a Ricardian model to produce a model capable of delivering the growth in the extensive margin that can be calibrated. We calibrate the model to the Mexican NAFTA experience in section 6, and extend the model to include an intensive margin as well as an extensive margin in section 8 . We perform sensitivity analysis in section 9 . 


\section{Measuring the Extensive Margin}

Our sample of countries is governed by the availability of consistent disaggregated data for countries that have undergone substantial trade liberalization. For reasons discussed below, we restrict the main discussion here to Canada, Mexico and the United States; these countries were party to the significant North American trade liberalization that took place in the 1980 s and 1990 s.

We begin with data on annual trade flow values, by good, for each pair of countries in the sample. The data on trade flows is reported according to the four-digit disaggregation of the Standard International Trade Classification, revision 2. In general, we study a ten-year window centered on the date of the event being considered. In some cases, however, consistent data is not available for all years. A complete list of countries, years and classifications is available in Table 1. To characterize the extensive margin, we must operationalize the definition of a nontraded good. We certainly want to include goods with zero trade in the set of nontraded goods, but we will also consider goods with very small amounts of trade as well. We refer to the goods in this set as the least traded goods.

To construct the set of least traded goods for a particular flow of exports, we order the SITC codes by their average value of trade in the first 3 years of the sample. ${ }^{3}$ We then cumulate the ordered codes to form 10 sets of codes, each representing one-tenth of total exports. The first set is constructed, starting with the smallest codes, by adding codes to the set until the sum of their values reaches one-tenth of total export value. The next set is formed by summing the smallest remaining codes until the value of the set reaches one-tenth of total export value. This procedure produces 10 sets of codes, each representing one-tenth of total trade. The first set consists of the least traded goods: the codes with the smallest export values, including all the SITC codes with a value of 0 . In order to create sets that account for exactly ten percent of total trade, some SITC codes had to be split. We split the last code added to a set such that the set accounts for exactly ten percent of trade, and the residual value of that code forms the beginning of the next set. For this reason, a set may be made up of a non-integer number of codes.

\footnotetext{
${ }^{3}$ Conceptually, we would prefer to rank the codes by their share of trade in output, as SITC codes are not of uniform size. Operationally, this requires data on gross output by four-digit SITC code for many countries, which is not available. For countries in which some measure could be constructed, the alternative ordering had little qualitative or quantitative impact on our results. We discuss this matter further in section 9.
} 
Given this system of partitioning the SITC codes, we consider two aspects of the data. First, we compute the change in the each set's share of trade over the sample period. Second, we follow the evolution of the least traded set of codes to highlight the timing of the growth in these goods.

The first measure compares the growth in trade of each of the 10 sets of codes. In the first year of the sample each set of codes is equal to 0.10 by construction. Holding fixed the composition of the 10 sets, we calculate the share of total exports for each of the 10 sets of codes in the last year of the sample period. To interpret this measure, consider the two extreme cases. If the growth in trade was driven only by a proportional increase in the value of goods already traded - that is, if the growth in trade were entirely on the intensive margin - each set of codes would retain its one-tenth share in trade, as in Figure 1. On the opposite extreme, if the growth in trade was driven only by trade in goods not previously traded that is, if the growth was only on the extensive margin - the set of least traded goods would gain trade share, while the trade shares of the other sets would decline, as in Figure 2

The second measure uses the same partition of SITC codes, but focuses only on the set of least traded goods. For each year in the sample, we compute the share of total exports accounted for by the codes in the least traded set. As in the first measure, if the elimination of trade barriers leads to trade in goods not previously traded, we should see an increase in the share of trade accounted for by this set of goods. More importantly, this measure allows us to see the timing of any changes in the trade of new goods. An increase in the share of exports that coincides with the implementation of trade reforms will provide strong evidence of the link between lower trade barriers and growth in the extensive margin.

A major obstacle in the implementation of the above procedures is the quality of disaggregated trade data. We require comparable data for many countries and years at as detailed level of classification possible. Finding consistent data, however, is difficult. The data recorded prior to and following the adoption of the Harmonized System (HS) of product classification is not clearly comparable at a detailed level. In particular, with the adoption of the Harmonized System of classification, disaggregated trade datasets are susceptible to potentially serious breaks around the year of the country's adoption of the HS, which is 1988 for most countries. The changes in aggregation schemes and product definitions have particularly severe effects on data from countries that were previously using a national classification system, such as the United States' Schedule B. An analysis of this 
problem with respect to the OECD's International Trade by Commodity Statistics data set and the World Trade Analyzer can be found in Kehoe and Ruhl (2004).

\section{Growth in the Extensive Margin}

Mindful of the data issues discussed in Kehoe and Ruhl (2004), we choose to use the International Trade by Commodity Statistics dataset from the OECD. In our analysis of North American trade liberalization, we consider the Canada U.S. FTA and the NAFTA together as one episode of liberalization. The CAFTA presents a slight data difficulty. The CAFTA was implemented in 1989, which is only one year after Canada adopted the HS classification. Thus, when we study the Canada-U.S. trade relationship, we use the sample period 1988-1998. A second complication arises from the later adoption of the HS by the U.S. in 1989. Data collected by the U.S. is therefore only comparable from 1989 onward. We circumvent this problem by using Canadian collected data on imports from the U.S. to measure the flow of trade from the U.S. to Canada and Canadian collected data on exports to the U.S. to measure the flow of trade from Canada to the United States. When studying the Canada-Mexico and Mexico-U.S. trade relationships, we use the data collected by Canada and the United States and a sample period of 1989-1999.

Using the procedure described above, we find significant growth in the extensive margin following trade liberalizations. Consider the results regarding the CAUSFTA/NAFTA. The first measure, which considers the changing export share of the ten categories based on initial export value, is presented for Mexican exports in Figure 3 and Figure 4. The approximately 663 SITC categories that accounted for the least traded 10 percent of exports from Mexico to the U.S. in 1989 were responsible for more than 17.2 percent of trade by the end of the sample period, an increase in export share of about 70 percent. The least traded goods account for 28.1 percent of exports from Mexico to Canada in 1999. The increasing share of trade attributed to these least traded goods provides strong evidence that decreases in trade barriers induce trade in goods that were previously nontraded. (Compare Figure 3 and Figure 4 to Figure 2.)

Table 3 lists the end of sample export shares of the least traded goods for all of the bilateral pairs associated with the CAUSFTA/NAFTA. The growth in the extensive margin is present for all of the NAFTA trading pairs. For Canada and Mexico, the extensive margin is particularly large, with Canadian least traded goods growing to more than four times its original trade share. A single code, unmilled wheat, (Inset code number here) accounts for 
almost half of the growth in trade share, but the remaining half is distributed over the other 737 codes. Rarely do single codes have an impact on our measure, as in the case of Canada and Mexico. The extensive margin growth for U.S. exports to Canada and Mexico are fairly small at 0.137 percent and 0.155 , respectively.

Figure 5 follows the trade share of the least traded goods from Mexico to the U.S. through the sample period. The sharp increase in the least traded goods' fraction of total trade coincides exactly with the implementation of the NAFTA in 1994. Figure 6 presents the same measure for exports from Mexico to Canada. Following the NAFTA liberalization, the trade share of the least traded goods almost triples. In both cases the shares had remained relatively constant prior to the NAFTA. The timing of the growth in the extensive margin provides strong evidence that this growth was related to the change in trade policies.

Further evidence that changing trade policy is behind the growth in the extensive margin, and not other factors such as product cycles, can be seen in Table 4. Here we compute the same measures of extensive margin growth for the United States and Japan, Germany and the United Kingdom. Of the top 5 trading partners of the U.S., these three have had no major trade reform with the U.S. over the sample period. None of these relationships shows large growth in the extensive margin. The extensive margin on U.S. exports to the United Kingdom did not grow at all over the period, and on Japan's exports to the United States it shows very little growth, with the least traded goods making up only 10.8 percent of trade at the end of the sample period. The largest increase in the extensive margin among the countries with stable trade policy was on Germany's exports to the U.S., whose least traded goods grew to only 14.3 percent of total trade at the end of the period. That we see extensive margin growth during times of trade liberalization, but do not see much extensive margin growth among countries that are not liberalizing trade further supports the idea that changes in trade policy induce countries to begin trading new kinds of goods.

Finally, we turn to the accessions of Greece, Portugal and Spain to the European Economic Community. Rather than report the numerous bilateral combinations, we aggregate exports to the other EEC countries and calculate the statistics as if they were from 
one partner country. ${ }^{4}$ Table 5 presents the results. All three countries show strong growth along the extensive margin, with Greece's least traded goods growing more than 400 percent in trade share. Figure 7 and Figure 8 show our measures of the extensive margin for Greece. As can be seen in Table 5, Portugal also has a large amount of growth in the extensive margin, with its least traded goods jumping to 20.9 percent after just the first two years of membership in the EEC. Spain's extensive margin growth is much smaller, but it is difficult to say whether there was no extensive margin growth, or if the growth happened later than in Portugal. The break in the data caused by the switch to the Harmonized System precludes us from following the evolution of Portugal and Spain after 1988.

\section{Alternative Measures}

As an alternative way of measuring the extensive margin, we use the decomposition developed in Hummels and Klenow (2004). (From hereon, the HK decomposition.) The technique decomposes country $i^{\prime}$ s share of world exports to country $j$ into two parts: the intensive and extensive export margins,

$$
\begin{gathered}
\text { Intensive Margin }{ }_{j}^{i}=\frac{\sum_{k \in K} x_{j k}^{i}}{\sum_{k \in K_{j}^{i}} x_{j k}^{W}} \\
\text { Extensive Margin }_{j}^{i}=\frac{\sum_{k \in K_{j}^{i}} x_{j k}^{W}}{\sum_{k \in K} x_{j k}^{W}},
\end{gathered}
$$

where the value of exports of good $k$ from country $i$ to country $j$ is denoted $x_{j k}^{i}$, and $x_{j k}^{W}$ is the value of exports from the world to country $j$ of good $k$. The set $K$ consists of all the SITC codes, while the set $K_{j}^{i}$ is made up of only the SITC codes in which country $i$ exports to country $j$, as determined by some cutoff value. Thus, if country $i$ exports many different goods to $j$, it would have a larger extensive margin, whereas, if it exported only a few goods to country $j$, it would have a larger intensive margin. Note that multiplying the

\footnotetext{
${ }^{4}$ For Greece, the other EEC countries are Belgium, Denmark, France, Germany, Ireland, Italy, Luxembourg, the Netherlands and the United Kingdom. For Portugal and Spain the EEC countries are the ones used for Greece, plus Greece, Portugal and Spain.
} 
intensive margin by the extensive margin returns country $i^{\prime} s$ share of world exports to $j, x_{j}^{i} / x_{j}^{W}$.

We use the HK decomposition to consider how the intensive and extensive margins grow over the sample period. We compute (1) and (2) for each year in the sample period, generating a time series measure of the intensive and extensive margins. We then take the growth rate of the extensive margin measured this way, and compare it to our own measure. The results for the NAFTA pairs are shown in Table 6. The first column of the table shows the percentage growth rates of our measure of the extensive margin. ${ }^{5}$ The second column shows the HK decomposition in which a good is considered nontraded if and only if exports are equal to zero, as in Hummels and Klenow (2004). The third column contains the HK decomposition computed with a cutoff value of $\$ 50,000$ as in Evenett and Venables (2002). Though our measure grows much more than the HK decompositions, the ordering of countries is similar. The two measures that employ fixed value cutoffs find almost no growth in the Canada-U.S. extensive margin, while the measures based on our relative cutoffs show modest growth. The HK measures reveal why: the United States and Canada were already trading amounts greater than $\$ 50,000$ of almost every good.

Since the U.S. and Canada are already trading nonzero amounts of many goods, it is difficult to pick up any extensive margin growth using fixed dollar definitions of tradedness. Our relative measure implies that any good being exported at less than $\$ 71,376,010$ from Canada to the U.S. is nontraded. ${ }^{6}$ However, the flow of exports from Canada to the U.S. is very large, so the value of a good exported to the U.S. from Canada in the amount of $\$ 71,376,010$ accounts for only 0.08 percent of the total trade flow. This good would be considered very traded by the fixed dollar measures considered. If one wanted to force these goods to be classified as nontraded under a fixed dollar measure one would need to increase the value of the cutoff, but if this cutoff is constant across all country pairs, the higher cutoff value creates problems measuring these other trade relationships. Total exports from Canada to Mexico are small compared to those to the U.S., and a constant cutoff across

\footnotetext{
5 To compute the HK decomposition we need data on a country's total imports by 4 digit SITC. We do not, unfortunately, have this data for Mexico until 1991 and for the United States until 1989. Thus, the sample period used in these comparisons is slightly different than the ones used in Table 3.

6 The $\$ 71,376,010$ cutoff is the value of the highest-valued good in the set of least traded goods for Canadian exports to the U.S in 1989.
} 
countries of $\$ 71,376,010$ would mean that a good valued at 14 percent of total Canadian exports to Mexico would be considered a nontraded good.

The above example highlights the underlying tension in dollar-value definitions of tradedness: a dollar value cutoff may understate the extensive margin in large trade relationships, and overstate the extensive margin in small trade relationships. This can be seen by comparing the Canada-U.S. trade relationship, which is big, to the Canada-Mexico relationship, which is small. ${ }^{7}$ Computing the HK decomposition with a cutoff of $\$ 50,000$ implies that the Canada-Mexico extensive margin grows about 31 times faster than the Canada-U.S. extensive margin. In comparison, our relative measure finds the CanadaMexico extensive margin growing only about 6 times the rate of the Canada-U.S. extensive margin.

As a robustness check, we consider the choice of our cutoff level. In addition to the 10 percent cutoff used in this paper, Table 7 reports the extensive margin growth rates for 5 percent cutoffs ( 20 sets of goods) and 20 percent cutoffs (5 sets of goods). Each column in Table 7 reports the percentage growth rate of the least traded goods for the given cutoff value. When we compute our measures using 5 percent rather than 10 percent cutoffs, the least traded goods grow faster in every relationship except for U.S. exports to Mexico, which stays almost constant. The increased growth with smaller cutoffs supports the idea that goods with very small trade shares are driving the extensive margin growth. The measure computed with 20 percent cutoffs grows slower in all cases, and has a simple mean of roughly half the measure using 10 percent cutoffs. As expected, larger cutoffs make the sets of goods too big to capture the growth in the least traded goods.

The preceding exercise makes it clear that the extensive margin is an important force in the growth in trade. The goods that made up only 10 percent of trade prior to liberalization regularly increase their share of trade by 40 percent or more following the decrease in trade barriers. For some countries these goods' share increases more than fourfold. This important feature, however, is not captured in many of the commonly used trade models, such as the factor proportions or monopolistic competition models. In the next section we present a Ricardian model that is capable of reproducing this growth in the extensive margin.

\footnotetext{
7 In 1989 , Canadian exports to the U.S. totaled $\$ 80$ billion, while Canadian exports to Mexico were $\$ 504$ million.
} 


\section{The Model}

We take as our point of departure the Ricardian model with a continuum of goods as in Dornbusch et al. (1977). We generalize the specification of comparative advantage in order to provide a model that can be calibrated to match the data on intra-industry trade. The model features two countries, $i=h, f$ and a continuum of goods indexed by $x \in[0,1]$. Each country possesses the technology to produce every good, $x$, but with differing unit labor requirements,

$$
y^{i}(x)=\frac{l^{i}(x)}{a^{i}(x)} \quad x \in[0,1]
$$

where $a^{i}(x)$ is the labor required to produce one unit of good $x$ in country $i$ and $l^{i}(x)$ is the amount of labor devoted to production of good $x$ in country $i$. Each country is endowed with labor, $L^{i}$, which is the only factor of production. There is a stand-in consumer is each country who supplies labor and chooses consumption in order to maximize

$$
U=\int_{0}^{1} \log \left(c^{i}(x)\right) d x
$$

subject to the budget constraint

$$
\int_{0}^{1} p^{i}(x) c^{i}(x) d x \leq w^{i} L^{i}
$$

and thus expenditure on any good, $x$, is

$$
c^{i}(x) p^{i}(x)=w^{i} L^{i}
$$

Each country can levy an ad valorem tariff of $\tau^{i}$ on imports, and tariff revenues are wasted. We take home country labor as the numeraire, normalizing the home wage to 1 .

\section{The Pattern of Trade}

A good is imported if it is less costly (including any tariffs) to do so than to produce it domestically. Thus, if

$$
\begin{gathered}
\left(1+\tau^{f}\right) a^{h}(x)<w^{f} a^{f}(x) \\
\frac{a^{h}(x)}{a^{f}(x)}<\frac{w^{f}}{1+\tau^{f}}
\end{gathered}
$$


then good $x$ is only produced in the home country and is exported to the foreign country. Similarly, if it is less costly to produce good $x$ in the foreign country,

$$
\frac{a^{h}(x)}{a^{f}(x)}>\left(1+\tau^{h}\right) w^{f}
$$

the good will only be produced in the foreign country, and will be exported to the home country. For producing growth in the extensive margin, the arrangement

$$
\frac{w^{f}}{1+\tau^{f}}<\frac{a^{h}(x)}{a^{f}(x)}<\left(1+\tau^{h}\right) w^{f}
$$

is important. In this case, good $x$ is produced in each country and is not traded. Goods that fall into this range are nontraded for the given level of tariffs, but may become traded as tariffs fall. This is the mechanism that generates extensive margin growth in response to a change in tariffs. The relative productivities of the two countries, along with the tariff rates and wages, completely determine the pattern of trade in this model. Next, we turn our attention to modeling relative productivity.

In the traditional expositions of this model, the relative productivities of the two countries are ordered such that

$$
\frac{a^{h}(x)}{a^{f}(x)}<\frac{a^{h}\left(x^{\prime}\right)}{a^{f}\left(x^{\prime}\right)} \quad \forall x, x^{\prime} \quad \text { s.t. } x<x^{\prime} .
$$

Although this formulation allows for an easy characterization of the trade pattern, it is hard to imagine a way to apply this ordering to the trade data available. Two major difficulties exist. First, trade data is collected in aggregates (such as SITC subgroups) which do not easily correspond to a particular good. Even in the absence of the first problem, we would still be faced with measuring the unit costs (or relative productivities) of individual goods across many countries.

Instead of imposing another arbitrary ordering on the goods, we take advantage of the ordering provided by the statisticians at the United Nations. The SITC defines groupings based on degree of processing and use, rather than some other criteria, such as major component of composition. For example, the Harmonized System groups wood figurines and wood charcoal together as wood products, while the SITC classifies wood charcoal into primaries and figurines into wood manufactures. (Pasteels (1998)) We apply 
the SITC ordering rule to our product space so that good 0000 lies on the left end of the interval, and good 9999 lies on the right end of the interval. Given this ordering, SITC codes are just subintervals of $[0,1]$. Having ordered the goods, we now proceed by assigning relative productivities to each good. Our approach is to assume that relative productivities are drawn from a distribution. We then calibrate this model by choosing the parameters of this distribution to match observations from the data. To construct the relative productivity curve, we take $J$ equally spaced points on $[0,1]$. For each of these points, let $\alpha_{j}$ denote the $\log$ of the relative productivities of good $x_{j}$,

$$
\alpha_{j}=\log \left(\frac{a^{h}\left(x_{j}\right)}{a^{f}\left(x_{j}\right)}\right) \quad j=1,2, \ldots, J
$$

We assume that the log-relative productivities of these $J$ goods are uniformly distributed. The distribution is parameterized by a single parameter, $\bar{\alpha}$,

$$
\alpha_{j} \sim \mathrm{u}[-\bar{\alpha}, \bar{\alpha}]
$$

This choice implies that the two countries, on average, have identical technologies. So that we can continue to work with a continuous product space, we connect $\alpha_{j}$ and $\alpha_{j+1}$ with a line, producing a continuous relative productivity schedule. The key parameters in this model are $\bar{\alpha}$ and $J$. These parameters determine the aggregate growth in trade and the amount of intraindustry trade.

For a given $J, \bar{\alpha}$ controls the number of nontraded goods, and thus the amount of trade growth, in the model by controlling the slope of the relative productivity schedule's segments. The effect of $\bar{\alpha}$ on the extensive margin can be seen in Figure 9 and Figure 10. In these figures we show a stylized version of the relative productivity curve in which $J$ is equal to 10 and only a few SITC codes are considered. The SITC codes are represented by the intervals marked on the on the horizontal axis in Figure 9 and Figure 10. Notice that some SITC codes are larger than others, as they are in the data. For a good to be nontraded, its relative productivity must lie between $w^{f} /\left(1+\tau^{f}\right)$ and $\left(1+\tau^{h}\right) w^{f}$. As tariffs fall, $w^{f} /\left(1+\tau^{f}\right)$ and $\left(1+\tau^{h}\right) w^{f}$ converge, and the goods that are forced out of this region change from being nontraded to traded. In Figure $9 \bar{\alpha}$ is low and the segments of the relative productivity curve are not very steep. In this case, lowering tariffs induces trade in 
many goods not previously traded. In Figure $10 \bar{\alpha}$ is high, and these segments are steeper, so fewer goods are forced out of the nontraded range defined by $w^{f} /\left(1+\tau^{f}\right)$ and $\left(1+\tau^{h}\right) w^{f}$. The number of points sampled in the interval, $J$, also has an effect on the number of nontraded goods in the model. More points imply smaller intervals between the points (since the measure of goods is fixed at 1), so for given values of $\alpha_{j}$ and $\alpha_{j+1}$, a higher value of $J$ yields a steeper segment of the relative productivity curve.

$J$ and $\bar{\alpha}$ also control the amount of intra-industry trade in the model. In order to produce intra-industry trade, the relative productivity curve must lie both above $\left(1+\tau^{h}\right) w^{f}$ and below $w^{f} /\left(1+\tau^{f}\right)$ within one SITC code. Given $J$ and the size of the SITC code, higher values of $\bar{\alpha}$ make the segments of the relative productivity curve steeper, increasing the likelihood of it laying above and below the nontraded zone within one code. The parameter $J$ influences the amount of intra-industry trade by controlling the number of times the relative productivity curve can change directions. If $J=2$, for example, the relative productivity curve would be a straight line between $\alpha_{1}$ and $\alpha_{2}$, and only one SITC code, at most, could have intra-industry trade. As $J$ is increased, the relative productivity curve, on average, changes direction more times, creating more opportunities for the curve to pass through the nontraded zone within one SITC code. In Figure 9 and Figure 10, the intervals marked on the horizontal axis represent individual SITC codes. Notice that some codes are much smaller than others are - as in the data. In Figure 10, in which $\bar{\alpha}$ is high, the shaded areas on the horizontal axis are the goods traded intra-industry. There is no intra-industry trade in Figure 9.

\section{Calibration}

To calibrate this model we need to specify values for the size of each SITC code, $L^{i}$, $J$ and $\bar{\alpha}$. Below we consider calibrating the model to the Mexico-U.S. trade relationship over the years 1989-1999.

Since we explicitly ordered the goods in our model according to their SITC ordering, an SITC code is an interval in $[0,1]$. To measure the size of each SITC code, the ideal measure is the code's share of total world output, 


$$
s_{k}=\frac{y_{k}^{M E X}+y_{k}^{U S A}}{\sum_{k \in K}\left(y_{k}^{M E X}+y_{k}^{U S A}\right)}
$$

where $y_{k}^{i}$ is the gross output of good $k$ in country $i$. However, gross output data at the detailed, comparable, level is not available. We instead measure SITC code size by its export share in total trade. This is certainly an imperfect measure, so we check the sensitivity of our results to this method in the next section. For each SITC code, $k$, we compute its share of total year 1989 trade,

$$
s_{k}=\frac{E X_{k}^{M E X}+E X_{k}^{U S A}}{\sum_{k \in K}\left(E X_{k}^{M E X}+E X_{k}^{U S A}\right)}
$$

where $E X_{k}^{i}$ is total exports of good $k$ by country $i$. We assign an interval of length $s_{k}$ to code $k$, in ascending order, such that $k=0011$ has 0.0 as its left endpoint, and $k=9999$ has 1.0 as its right endpoint.

It remains to specify values for $J$ and $\bar{\alpha}$. These parameters jointly determine the amount of intra-industry trade between the two countries and the increase in the value of total trade following a decrease in tariffs. To measure intra-industry trade, we compute the Grubel and Lloyd (1971) index at the four-digit SITC level for 1989, which is defined as

$$
g_{M E X}^{U S}=1-\frac{\sum_{k \in K}\left|E X_{M E X, k}^{U S A}-E X_{U S A, k}^{M E X}\right|}{\sum_{k \in K}\left(E X_{M E X, k}^{U S A}+E X_{U S A, k}^{M E X}\right)}
$$

where $E X_{i, k}^{j}$ is the value of exports of good $k$ from country $j$ to country $i$. The index runs from 0 , if there is no intra-industry trade, to 1 if the countries export as much of each good as they import. The Grubel-Lloyd index in 1989 is 0.487 , reflecting substantial intra-industry trade between the United States and Mexico.

To measure the growth in trade, we calculate the fraction of U.S. and Mexican production that is traded in 1989 and 1999. Since trade data is measured as shipment value, and not value added, gross output is the correct measure of production. We include only the production of agriculture, mining and manufactures, as our trade data covers only these three commodity types. We also adjust output to match the structure of our two-country model. To do this, we exclude production that is traded to other countries, by subtracting exports to these countries from gross output. This yields a measure of output that is either 
consumed domestically, or traded to the partner country: the only two possibilities in the model. We use the geometric average of the two countries' shares. This average share increased 202 percent over the sample period.

The country size parameters are calibrated to the relative outputs of the countries being considered. Again, we use the U.S. dollar value of gross output in the agriculture, mining and manufacturing sectors. We take the average of the ratio of gross output of Mexico to the United States over the period 1980-2000. This implies that the United States is about 20 times larger than Mexico. The calibration is summarized in the following table.

Table 1

\begin{tabular}{ccc}
\hline Parameter & Value & Fact (Value) \\
\hline$\frac{L^{M E X}}{L^{U S A}}$ & 0.062 & Relative Output/Working Aged Person $(0.062)$ \\
\hline$J$ & 4251 & Growth in Trade Share of Production $(202 \%)$ \\
$\bar{\alpha}$ & 0.223 & Grubel-Lloyd Index $(0.487)$ \\
\hline
\end{tabular}

\section{Model Results}

Each realization of the relative productivity schedule defines a different economy. For a given realization of the relative productivity schedule, we solve the model with tariffs set at 15 percent. Next, using the same relative productivity schedule, we lower the tariff rate to 5 percent and solve for the new equilibrium. Using our mapping of STIC codes in the model, we can calculate our measure of the extensive margin as we did in section 3 . We repeat this procedure for 1000 realizations of the relative productivity schedule, each time solving the model and computing our measure of the extensive margin. We present our results as the average trade shares over the 1000 simulations, as well as a two standard deviation interval centered on the mean. Figure 11 compares the calibrated model with the data. The model does a good job generating growth in new goods. The least traded goods in the model make up 25.2 percent of trade in 1999, compared to 17.2 percent in the data. Using the same methods described above, we also calibrate the model to match the MexicoCanada trade relationship. Figure 12 reports the results for this calibration. The least traded goods make up 46.9 percent of trade in 1999 , versus 28.1 percent in the data. 
The model's large extensive margin growth is a result of two factors. First, the model has no margin for growth in goods already traded, so all growth in trade must come from trading new goods. Second, we calibrate the model to match the enormous growth in trade these countries have experienced. By forcing the model to produce the large amount of trade growth using only the extensive margin we overshoot the amount of trade in new goods. In the next section, we modify the model to allow for growth on the intensive margin.

\section{Modeling the Intensive and Extensive Margins}

In this section we consider a model with an intensive margin and an extensive margin. To do so, we leave the basic setup of the model unchanged, but specify consumers' preferences over goods to be of the constant elasticity of substitution type,

$$
U=\left(\int_{0}^{1} c^{i}(x)^{\frac{1}{\rho}} d x\right)^{\rho} .
$$

This specification adds a new parameter, $\rho$, to the model, which is related to the elasticity of substitution between goods, $\sigma$, by

$$
\sigma=\frac{1}{1-\rho}
$$

As is common with this specification of preferences, we can think of $U$ as a composite good, and derive the price of this good as

$$
P^{i}=\left(\int_{0}^{1} p^{i}(x)^{1-\sigma} d x\right)^{\frac{1}{1-\sigma}}
$$

and the expenditure on any good as

$$
c^{i}(x) p^{i}(x)=w^{i} L^{i}\left(\frac{p^{i}(x)}{P^{i}}\right)^{1-\sigma} .
$$

The above relation is the key difference between the model with and without the intensive margin. Suppose that good $x$ is already traded. In the model with only the extensive margin we can see from (6) that expenditure on this good remains unchanged following the decrease in tariffs. However, as can be seen in (20), as tariffs are lowered and the delivered price falls, expenditure on this good will increase following the decrease in tariffs, given 
that $\sigma>1$. This intensive margin growth should relieve some of the responsibility for generating trade growth that was before solely shouldered by the extensive margin.

In the model with Cobb-Douglas preferences, we did not have to keep track of the prices of the goods, since expenditure on each good was constant at $w^{i} L^{i}$. Under the more general constant elasticity of substitution preferences, we need all of the prices to solve the model, and to know the prices, we must know all the unit costs, rather than just the ratios. We use the same uniform distribution to assign the ratio of log relative productivities, and pin down the unit cost levels with a normalization. We assume that $a^{h}\left(x_{j}\right) a^{f}\left(x_{j}\right)=1$ so the $\log$ productivities are fractions of the relative productivity.

$$
\log \left(a^{h}\left(x_{j}\right)\right)=\frac{\alpha_{j}}{2} \quad \log \left(a^{f}\left(x_{j}\right)\right)=-\frac{\alpha_{j}}{2} \quad j=1, \ldots, J
$$

We solve this version of the model as we did the earlier one, by drawing 1000 relative productivity schedules, solving the model for each realization and averaging across the realizations. We calibrate this version of the model to the same facts as before. There is considerable debate as to what value should be used for the elasticity of substitution. As pointed out by Yi (2003) and others, in standard trade models an elasticity around 14 is needed to match the growth in trade following tariff reductions. For the exercise here, we choose the elasticity to be 9, similar to those found in Bergoeing, Kehoe, Kehoe and Soto (2002) and Chari, Kehoe and McGrattan (2002). Figure 13 and Figure 14 compare the model's results with the data. The model with the intensive margin does a slightly better job of producing the aggregate growth in trade without producing excessively large amount of extensive margin growth. In the model of Mexican exports to the U.S., the model with an intensive margin generates an after liberalization share of the least traded goods of 0.22 compared to 0.25 in the model with only an extensive margin. In the Mexico-Canada model, the model with the intensive margin has an after liberalization share of 0.38 compared to 0.48 in the model with only an extensive margin.

As an alternative experiment, we could treat the elasticity of substitution parametrically, and search for the elasticity that allows for exactly as much extensive margin growth as we find in the data. In the case of Mexico and Canada, we needed an elasticity of 12.35 in order to match the extensive growth of 28.1 percent found in the data. In the case of Mexico and the United States, an elasticity of substitution around 14 is needed to match 
the data. The elasticities needed to match the model to the data are a bit higher than those found in the literature. These high elasticities are also the result of forcing the model to produce the growth in aggregate trade levels. A major problem in the international trade literature is the inability of the workhorse models to produce the large observed growth in trade given the small observed change in tariffs. Basic monopolistic competition models, international real business cycle models and even the Ricardian model, on which our model is built, suffer from this problem. ${ }^{8}$ We return to this elasticity puzzle in Chapter 2. However, given this inherited (and common) problem, our model performs as well as the standard models in producing the aggregate trade growth. Where it advances beyond these models is in its ability to reproduce the observed extensive margin growth, and provide a simple and calibratable Ricardian economy.

\section{Sensitivity Analysis}

The use of trade flows as a proxy for output in measuring the size of an SITC code is potentially a source of concern. Some industries may export a larger fraction of their output than might others, leading to a very different "industry size" when measured by trade share rather than production share. However, this problem may not be as worrisome as it first seems. Since we are not making predictions about individual industries, the idea that an industry may be measured as "large" by output and "small" by trade volume is not necessarily a problem. If this industry is offset by another that is measured "small" by output and "large" by trade volume, our results should be unaffected. We only need the distribution of industry sizes to be similar. In this section we check the sensitivity of the model's results to our choice of measurement.

Data on production (gross output - not value added) is difficult to obtain at a very disaggregated level, particularly comparable data for many countries. In order to keep the data comparable across countries we collect data on gross output from Mexico and the United States at the four-digit level of the International Standard Industrial Classification (ISIC). Unfortunately, this yields only 96 different groups, compared to the 789 four-digit SITC codes. We map the SITC codes into the ISIC groups, and divide the production value from each ISIC group evenly across the relevant SITC codes. This crude mapping yields a

\footnotetext{
8 See Yi (2002) for an overview of the failure of these models in this area. He shows that elasticities of substitution in the range of 12 to 14 are needed in these models to match the observed U.S. trade growth given a 15 percent tariff reduction.
} 
series of gross output by SITC codes, which is then normalized to lie in the unit interval as described above in the calibration section.

Figure 15 compares the two series. The two methods produce series that are very similar except for the largest industries. The ten largest industries as measured by trade volume are, on average, 6.6 times larger than the ten largest industries by production. Much of this difference is probably driven by the equal assignment of production values to indistinguishable SITC codes under our crude concordance.

Given the difference in the large industries between the two methods, it is worthwhile to see how the model's results change when using the production series to measure industry size. We recalibrate the Mexico-U.S. model (with only the extensive margin) exactly as before, except we use the production numbers to create the SITC codes on the unit interval. The most significant change in the parameter values is the higher value of $J$, the number of times the relative productivity curve can change directions. In the model, large industries tend to have more intra-industry trade, so shrinking the largest industries requires the intra-industry trade be made up in the other industries. To get more intra-industry trade in the smaller industries, on average, we need the relative productivity curve to change directions more often, creating more chances for intra-industry trade.

The results of the model under the two different measuring schemes are shown in Figure 16. The model using the output measure produces an export share of 0.261 for the least traded goods, compared to the 0.250 share in the model using the trade measure. Using the trade data, our mapping created a series with some large industries, whereas the output data creates a series containing fewer large industries. Given that the true distribution of industry size lies somewhere in-between the two, the small spread between the results suggests our results are robust to measurement error in the size of the SITC codes.

\section{Concluding Remarks}

In this chapter we have provided evidence of an important, yet little discussed feature of trade growth: the extensive margin. After studying 5 major trade liberalizations, we find that trade in goods that were not before traded shows substantial growth following a decrease in trade barriers. For some countries, the collection of goods that accounted for only 10 percent of trade prior to the liberalization more than quadruples its share in only a few years following the liberalization. Most of the applied models of international trade have 
neglected this characteristic of the data. By modifying a standard Ricardian framework, we provide a simple model that is capable of reproducing this growth in the extensive margin. 


\section{References}

Alessandria, G. and H. Choi (2003), "Export Decisions and International Business Cycles," University of Auckland and Ohio State University

Bergoeing, R., P. J. Kehoe, T. J. Kehoe and R. Soto (2002), “A Decade Lost and Found: Mexico and Chile in the 1980s," Review of Economic Dynamics, 5(1), 166-205.

Bernard, A. B., J. Eaton, J. B. Jensen and S. Kortum (2003), "Plants and Productivity in International Trade," American Economic Review, 93(4), 1268-1290.

Chari, V. V., P. J. Kehoe and E. R. McGrattan (2002), "Can Sticky Price Models Generate Volatile and Persistent Real Exchange Rates?," Review of Economic Studies, 69(3), 53363.

Dornbusch, R., S. Fischer and P. A. Samuelson (1977), "Comparative Advantage, Trade, and Payments in a Ricardian Model with a Continuum of Goods," American Economic Review, 67(5), 823-39.

Eaton, J. and S. Kortum (2002), “Technology, Geography, and Trade,” Econometrica, 70(5), 1741-79.

(2002), "Export Growth by Developing Economies: Market Entry and Bilateral Trade,"

Grubel, H. G. and P. J. Lloyd (1971), “The Empirical Measurement of Intra- Industry Trade," Economic Record, 47(120), 494-517.

Hillberry, R. H. and C. A. McDaniel (2002), "A Decomposition of North American Trade Growth since NAFTA,” U.S. International Trade Commission Working Paper 2002-12-A.

Hummels, D. and P. J. Klenow (2004), “The Variety and Quality of a Nation's Exports,”

Kehoe, T. J. and K. J. Ruhl (2004), "The Consistency of Disaggregated Trade Data,"

Kraay, A. and J. Ventura (2002), "Trade Integration and Risk Sharing," European Economic Review, 46(6), 1023-48.

Melitz, M. J. (2003), "The Impact of Trade on Intra-Industry Reallocations and Aggregate Industry Productivity," Econometrica, 71(6), 1695-1725.

Mukerji, P. (2004), "Trade Liberalization and the Extensive Margin,"

(1998), "Foreign Trade Statistics: A Basic Market Research Tool,”

Ruhl, K. J. (2003), "Solving the Elasticity Puzzle in International Economics,"

Sandrey, R. and D. van Seventer (2004), "Has the New Zealand/Australian Closer Economic Relationship (CER) Been Trade Widening or Deepening?," 2004. 
Yi, K.-M. (2003), "Can Vertical Specialization Explain the Growth of World Trade?,” Journal of Political Economy, 111(1), 52-102. 
Table 2

Data Availability by Country, Year and Classification

\begin{tabular}{lll}
\hline Country & Time Period & Classification \\
\hline Canada & $1988-1989$ & SITC Revision 2 \\
Germany & $1989-1999$ & SITC Revision 2 \\
Greece & $1979-1986$ & SITC Revision 2 \\
Japan & $1989-1999$ & SITC Revision 2 \\
Mexico & $1989-1999$ & SITC Revision 2 \\
Portugal & $1982-1987$ & SITC Revision 2 \\
Spain & $1982-1987$ & SITC Revision 2 \\
United Kingdom & $1989-1999$ & SITC Revision 2 \\
United States & $1989-1999$ & SITC Revision 2 \\
\hline
\end{tabular}

Table 3

Share of Export Value Accounted for by the Least Traded Goods Following CAUSFTA/NAFTA

\begin{tabular}{lll}
\hline Period & Trade Flow & Share of Total Exports \\
\hline $1989-1999$ & Mexico to United States & 0.172 \\
$1989-1999$ & United States to Mexico & 0.155 \\
$1989-1999$ & Mexico to Canada & 0.281 \\
$1989-1999$ & Canada to Mexico & 0.415 \\
$1988-1998$ & Canada to United States & 0.171 \\
$1988-1998$ & United States to Canada & 0.137 \\
\hline
\end{tabular}


Table 4

Share of Export Value Accounted for by the Least Traded Goods

Countries with Stable Trade Policy

\begin{tabular}{lll}
\hline Period & Trade Flow & Share of Total Exports \\
\hline $1989-1999$ & United States to United Kingdom & 0.100 \\
$1989-1999$ & United Kingdom to United States & 0.129 \\
$1989-1999$ & United States to Japan & 0.132 \\
$1989-1999$ & Japan to United States & 0.108 \\
$1989-1999$ & United States to Germany & 0.125 \\
$1989-1999$ & Germany to United States & 0.143 \\
\hline
\end{tabular}

Table 5

Share of Export Value Accounted for by the Least traded Goods Following Accession to the EEC

\begin{tabular}{lll}
\hline Period & Trade Flow & Share of Total Exports \\
\hline $1978-1986$ & Greece to the EEC & 0.502 \\
$1982-1987$ & Spain to the EEC & 0.139 \\
$1982-1987$ & Portugal to the EEC & 0.209 \\
\hline
\end{tabular}


Table 6

Percent Growth Rates: Kehoe-Ruhl Measure and Hummels-Klenow Measure

\begin{tabular}{lcccc}
\hline & $\begin{array}{c}\text { Kehoe-Ruhl } \\
\mathbf{1 0 \%} \text { Cutoff }\end{array}$ & $\begin{array}{c}\text { Hummels-Klenow } \\
\mathbf{\$ 0} \text { Cutoff }\end{array}$ & $\begin{array}{c}\text { Hummels-Klenow } \\
\mathbf{\$ 5 0 , 0 0 0} \text { Cutoff }\end{array}$ & $\begin{array}{c}\text { Hummels-Klenow } \\
\text { Cutoff Implied by } \\
\text { Kehoe-Ruhl 10\% }\end{array}$ \\
\hline $\begin{array}{l}\text { USA to CAN } \\
\text { 1988-1999 } \\
\text { CAN to USA }\end{array}$ & 36.8 & 0.0 & 0.0 & 12.0 \\
$\begin{array}{l}\text { 1989-1999 } \\
\text { USA to MEX }\end{array}$ & 59.9 & 1.5 & 2.0 & 34.4 \\
$\begin{array}{l}\text { 1991-1999 } \\
\text { MEX to USA }\end{array}$ & 71.7 & 17.2 & 17.4 & 44.9 \\
$\begin{array}{l}\text { 1989-1999 } \\
\text { MEX to CAN }\end{array}$ & 180.8 & 1.4 & 2.1 & 25.8 \\
$\begin{array}{l}\text { 1989-1999 } \\
\text { CAN to MEX }\end{array}$ & 386.0 & 15.9 & 23.8 & 45.9 \\
$1991-1999$ & 36.2 & 61.9 & 181.4 \\
\hline
\end{tabular}

Table 7

Results under Different Cutoff Values

\begin{tabular}{llrcc}
\hline \multicolumn{4}{c}{ Percentage Growth Rate of Export Share: } & Least traded Goods \\
\hline & & $\mathbf{5 \%}$ & $\mathbf{1 0} \%$ & $\mathbf{2 0} \boldsymbol{\mathbf { 0 }}$ \\
\hline $1989-1999$ & Mexico to U.S. & 128.7 & 71.7 & 32.8 \\
$1989-1999$ & U.S. to Mexico & 54.4 & 55.0 & 38.8 \\
$1989-1999$ & Mexico to Canada & 354.9 & 180.8 & 102.9 \\
$1989-1999$ & Canada to Mexico & 610.5 & 315.1 & 171.8 \\
$1988-1998$ & Canada to U.S. & 107.0 & 70.4 & 47.0 \\
$1988-1998$ & U.S. to Canada & 61.3 & 36.8 & 29.0 \\
$1976-1986$ & Greece to EEC & 844.7 & 401.9 & 186.5 \\
$1981-1987$ & Spain to EEC & 80.2 & 38.8 & 19.3 \\
$1981-1987$ & Portugal to EEC & 201.4 & 109.8 & 67.5 \\
\cline { 2 - 4 } & Average & 271.5 & 142.3 & 77.3 \\
\hline
\end{tabular}


Figure 1

\section{Composition of Exports \\ Sets of Categories Based on Export Size}

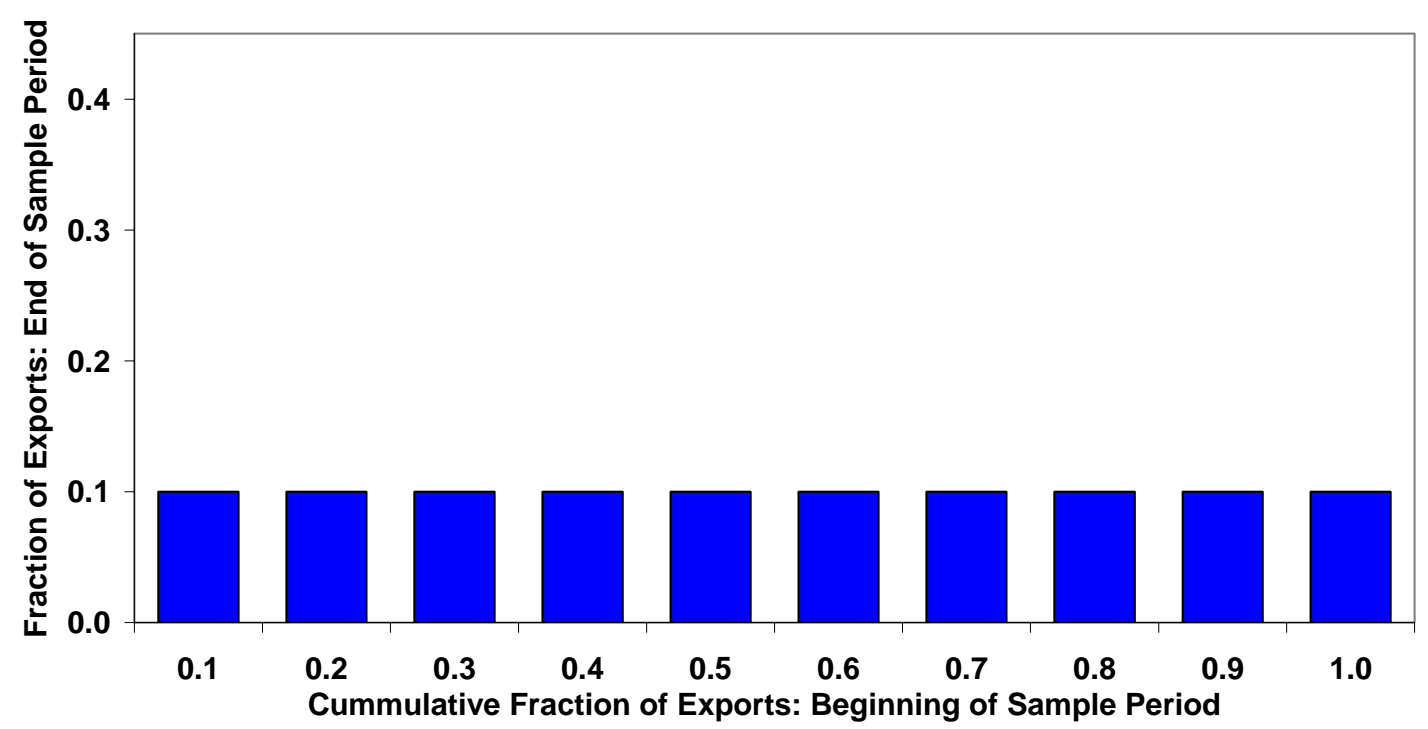

Figure 2

Composition of Exports

Sets of Categories Based on Export Size

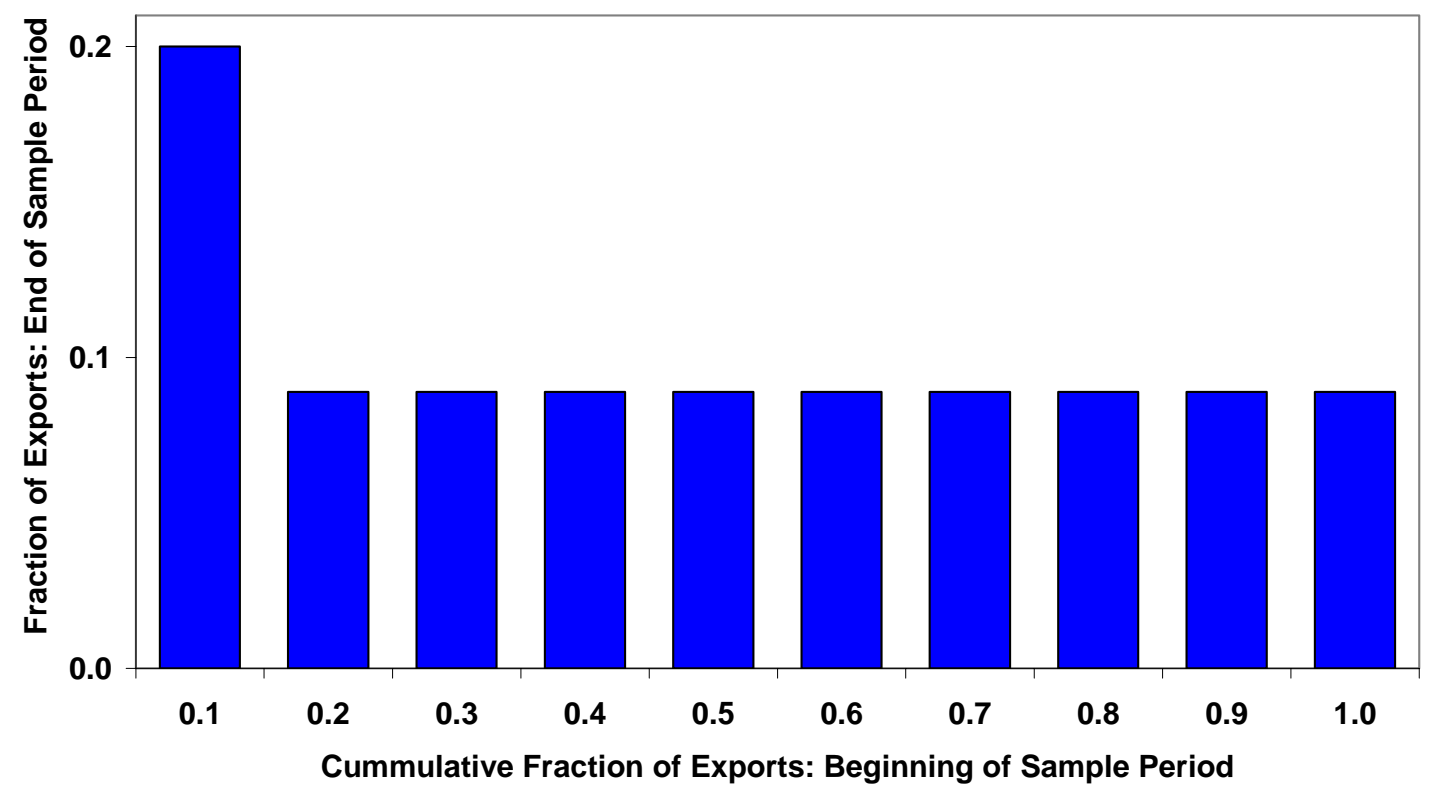


Figure 3

Composition of Exports: Mexico to U.S. 1989-1999

By Sets of Categories Based on Export Size

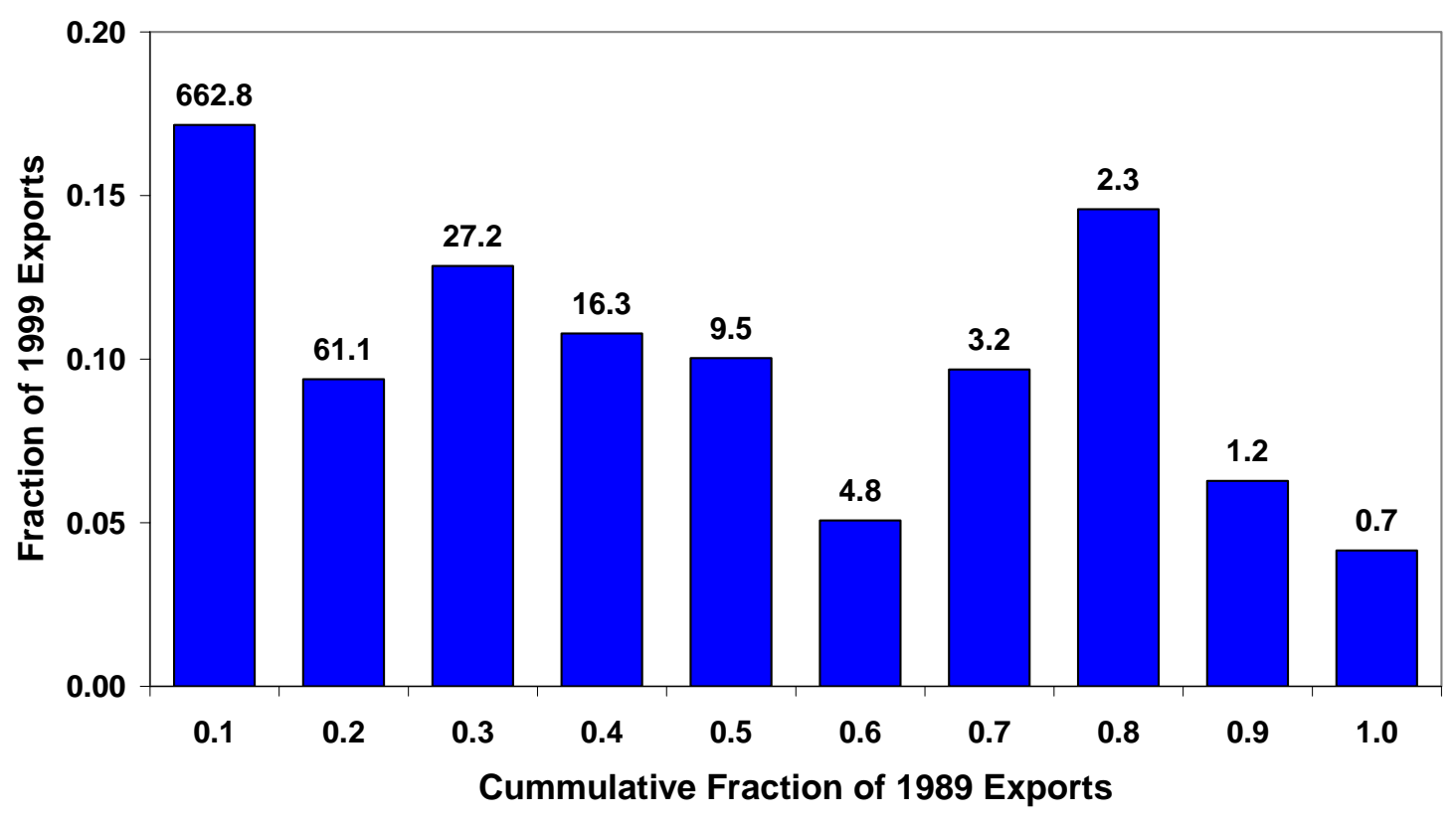

Figure 4

Composition of Exports: Mexico to Canada 1989-1999

By Sets of Categories Based on Export Size

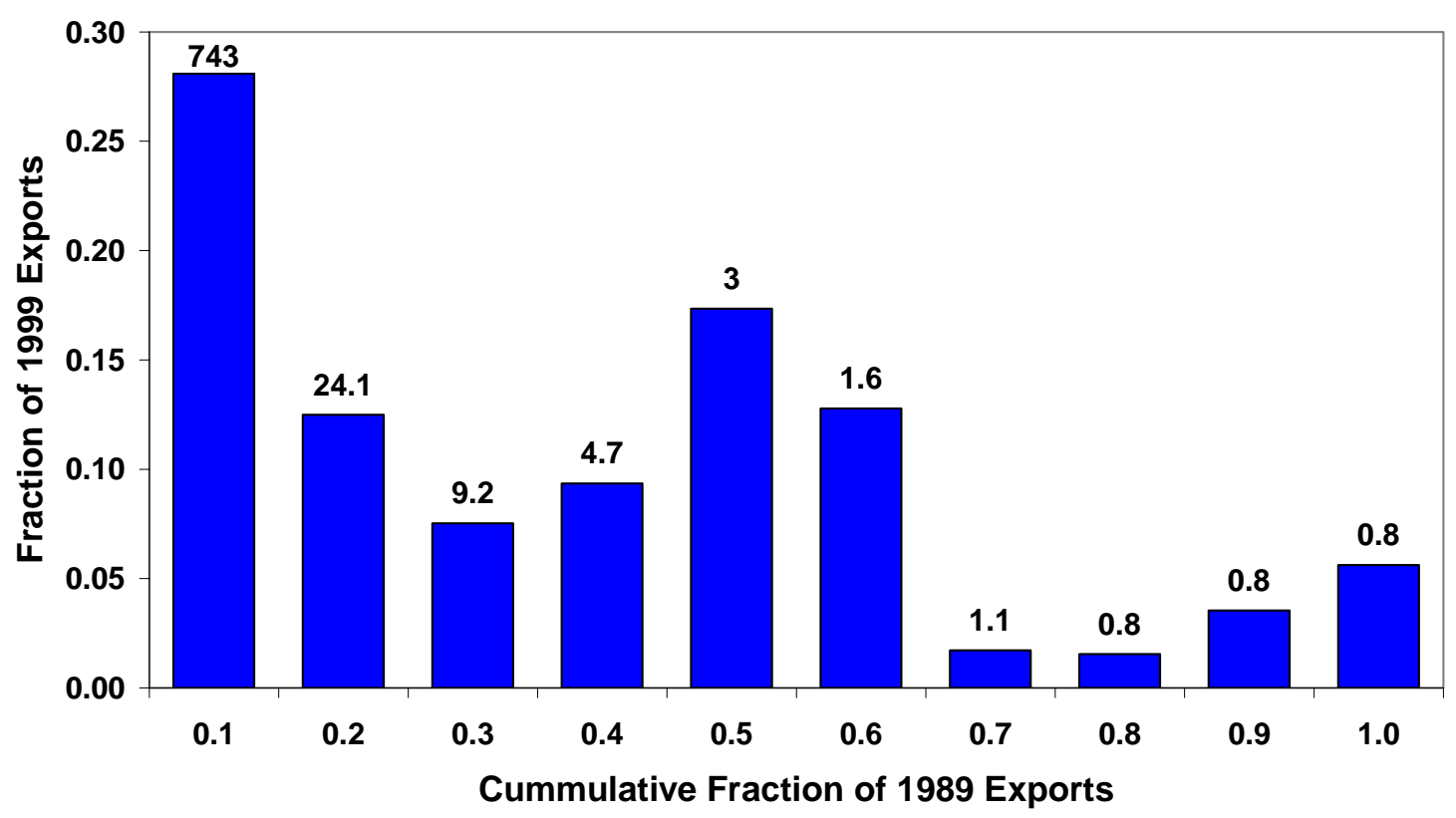


Figure 5

Exports: Mexico to U.S.

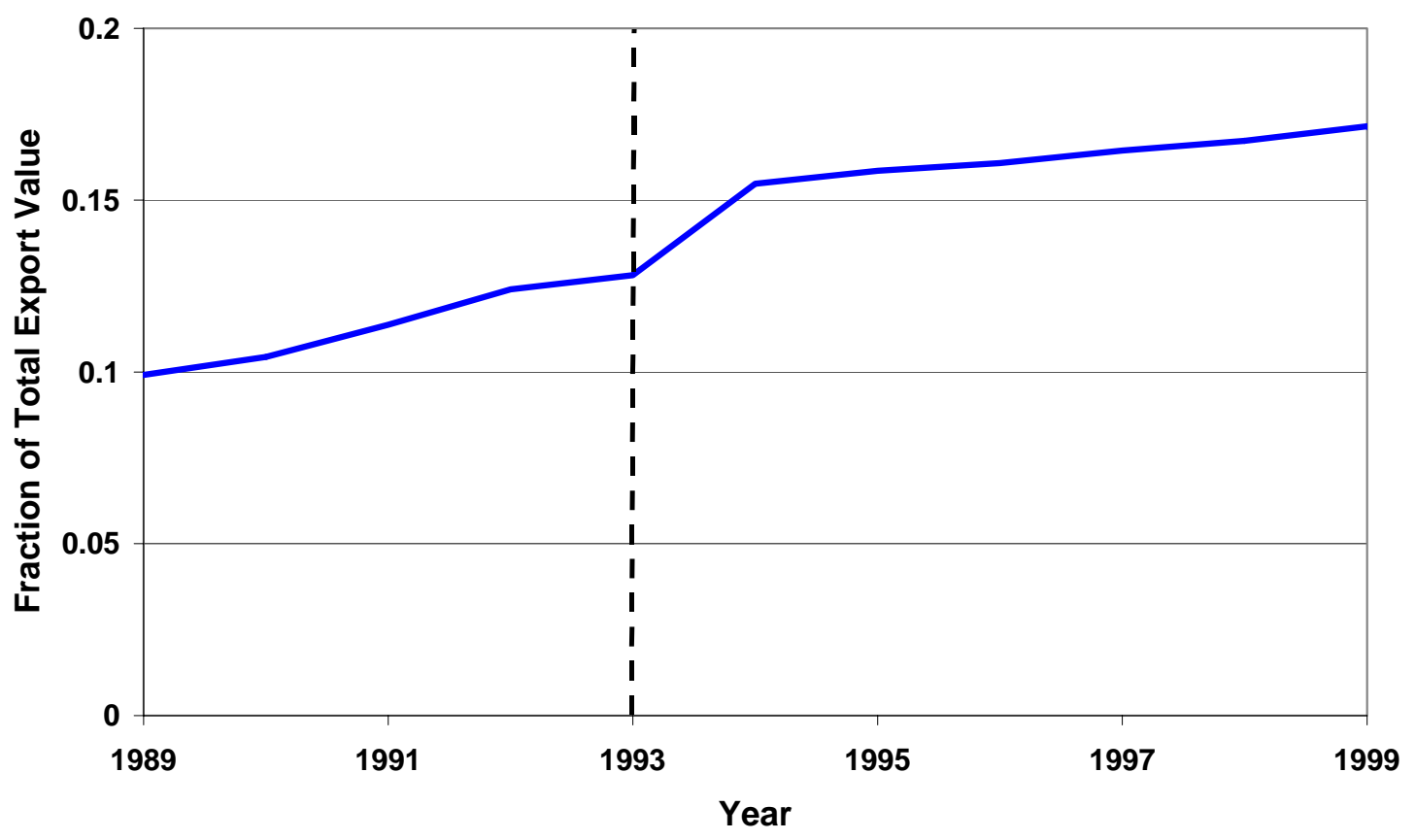

Figure 6

Exports: Mexico to Canada

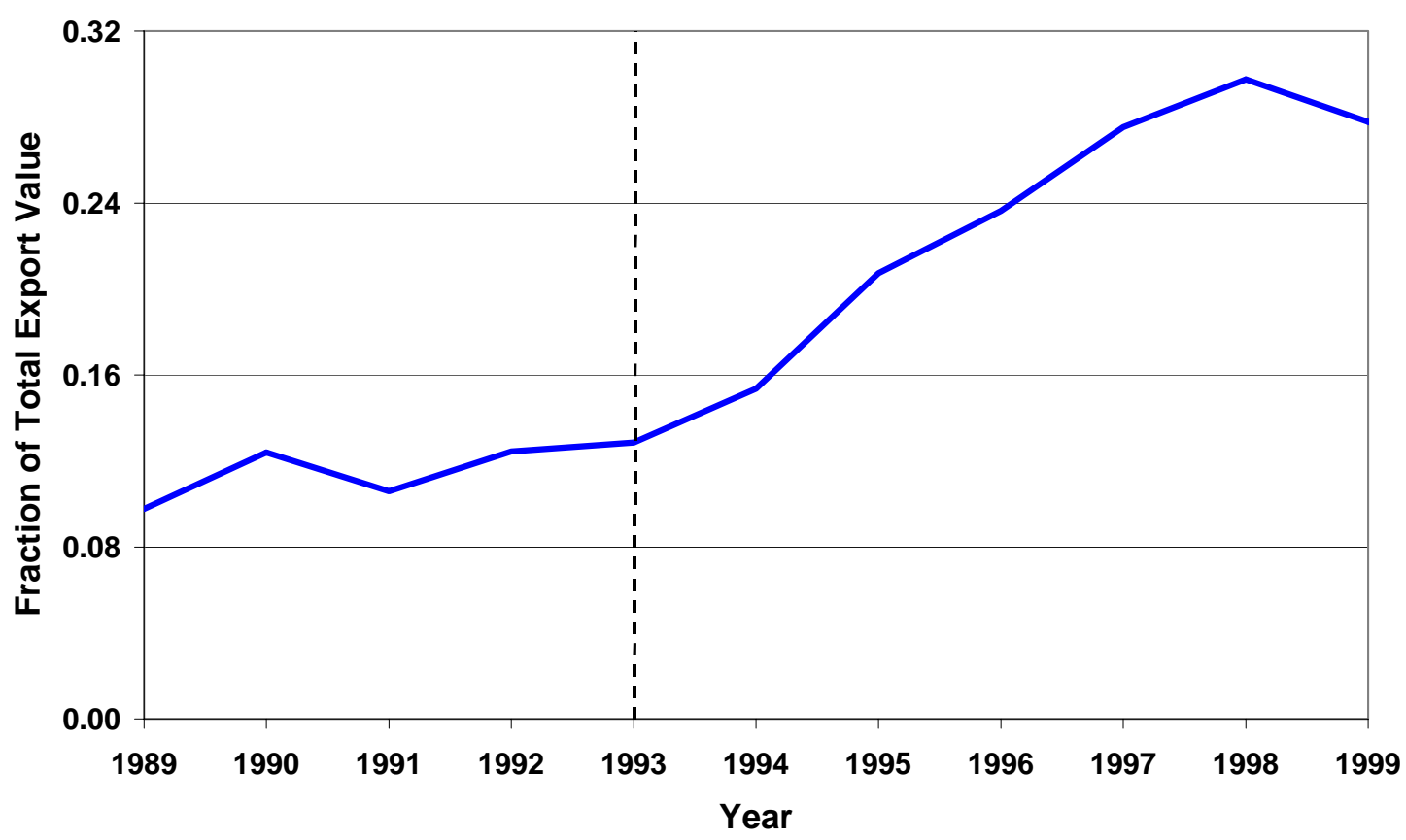


Figure 7

Composition of Exports: Greece to the EEC 1979-1986

By Sets of Categories Based on Export Size

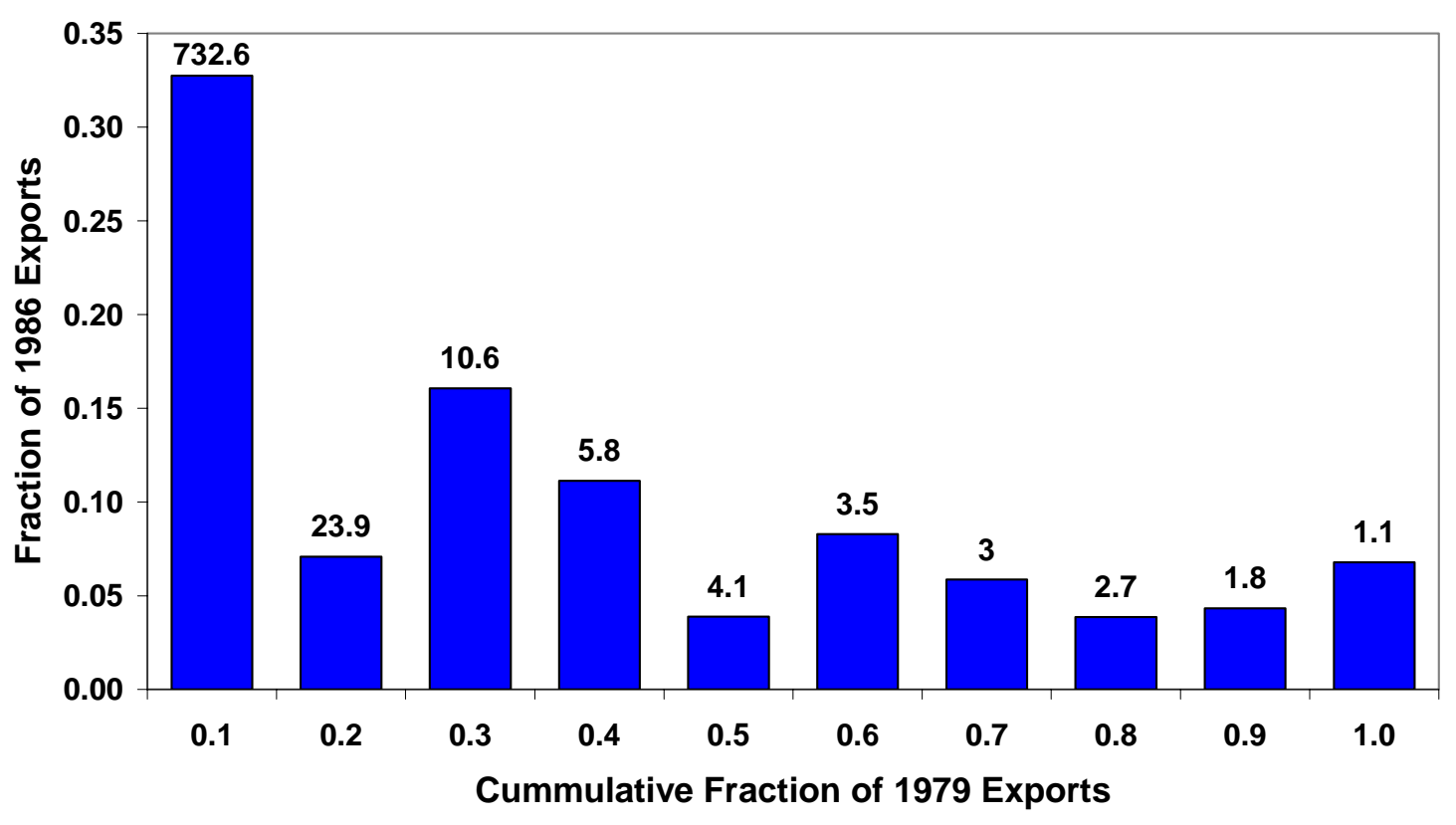

Figure 8

Exports: Greece to EEC

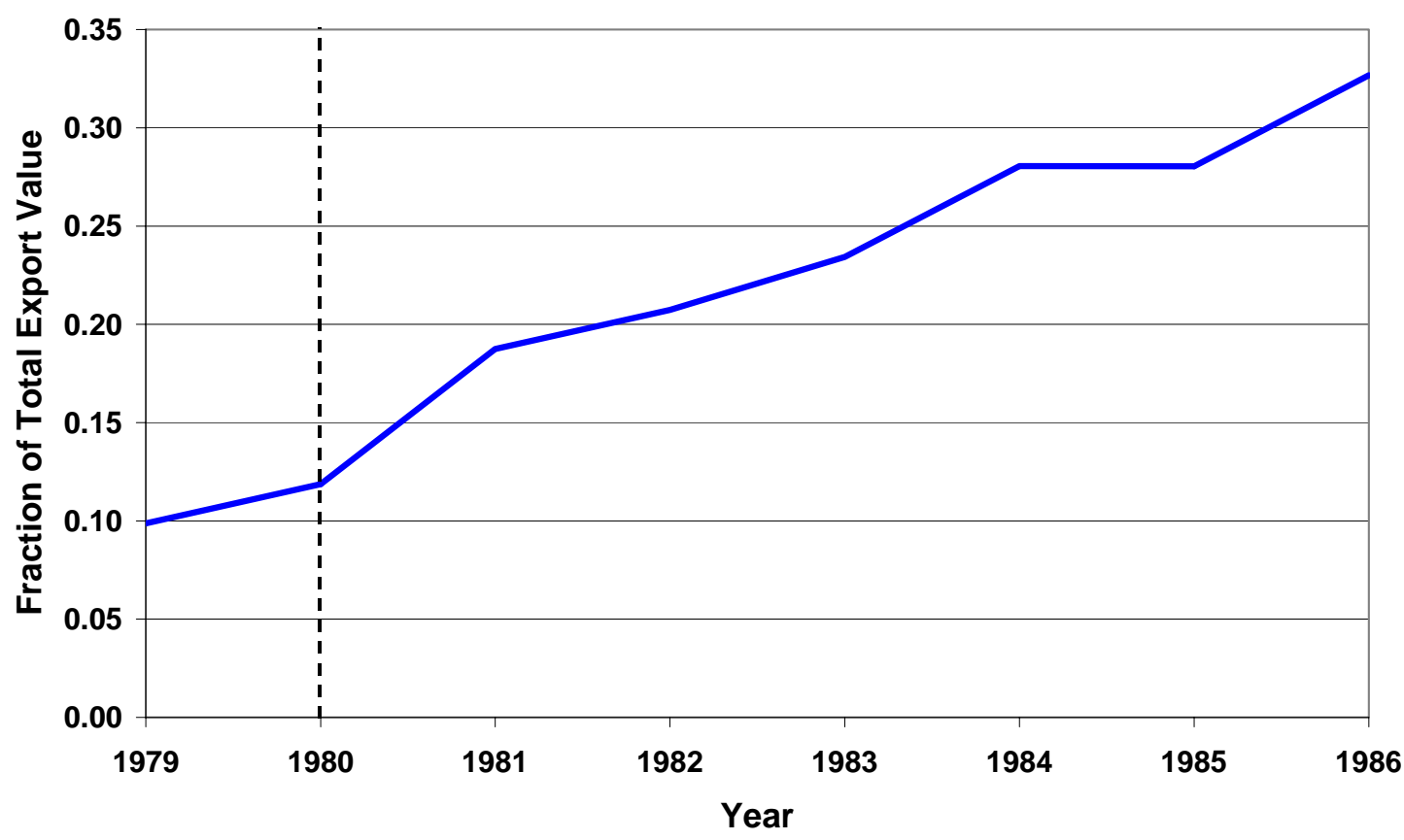


Figure 9

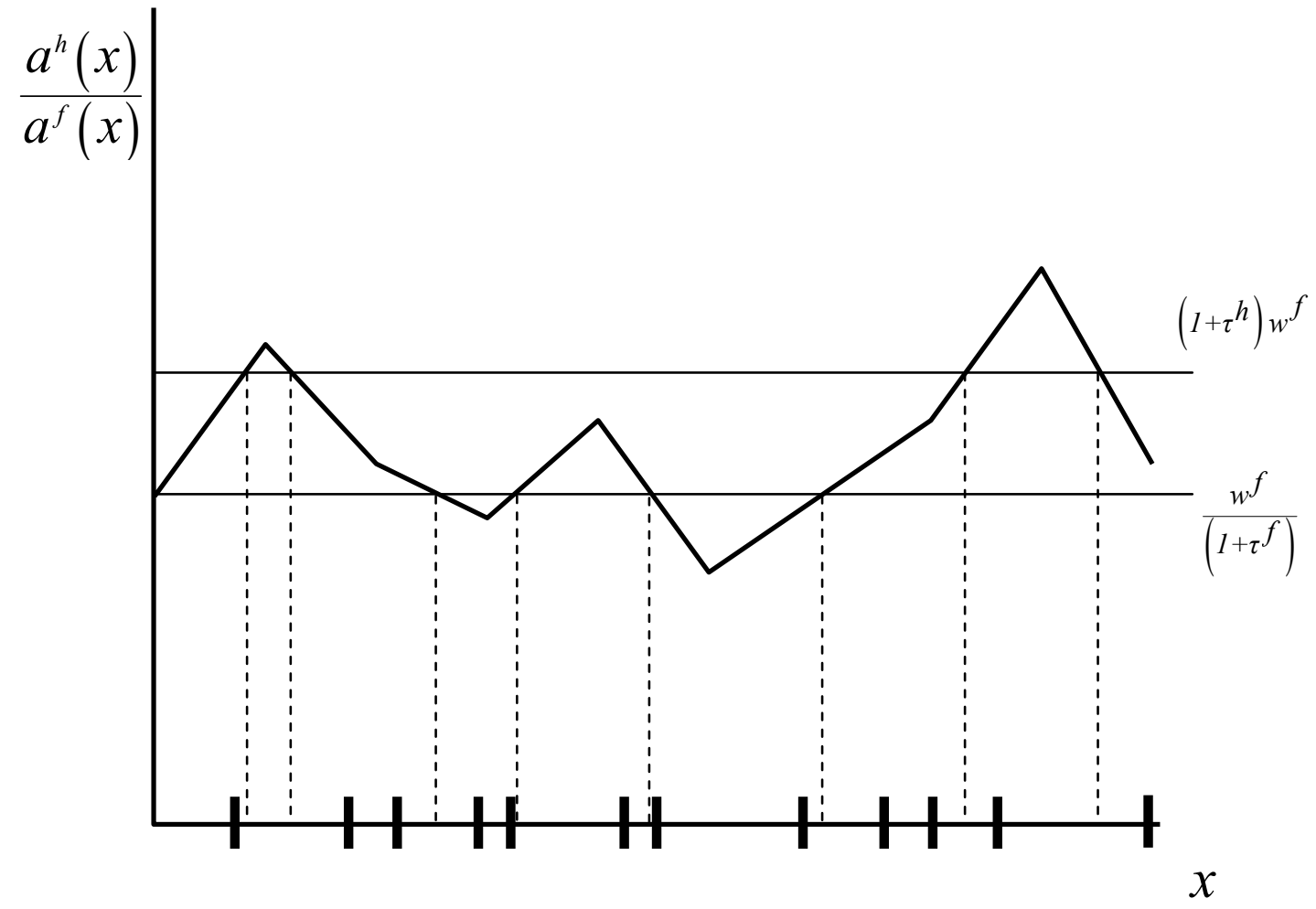

Figure 10

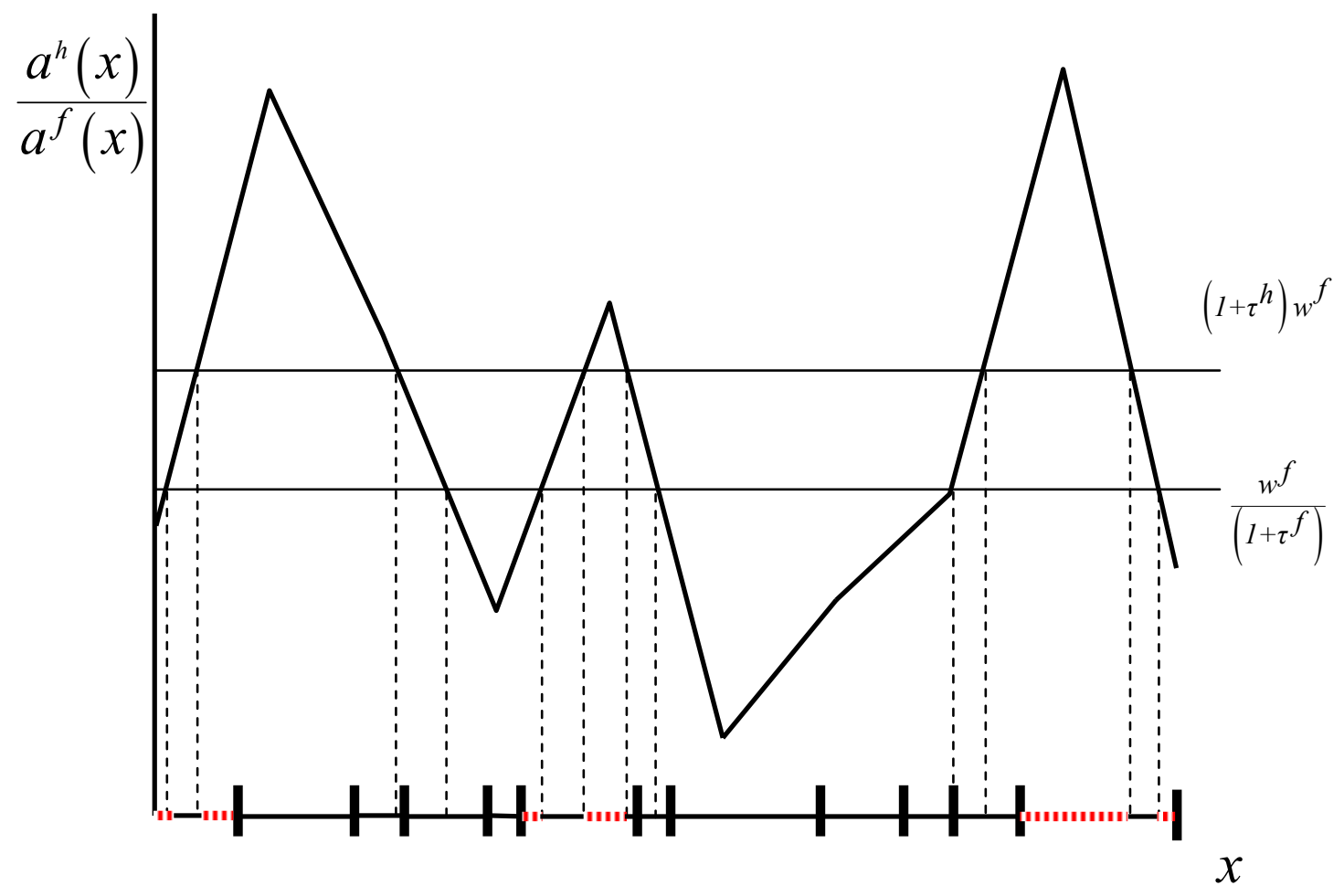


Figure 11

Composition of Exports: Mexico to U.S. 1989-1999

By Sets of Categories Based on Export Size

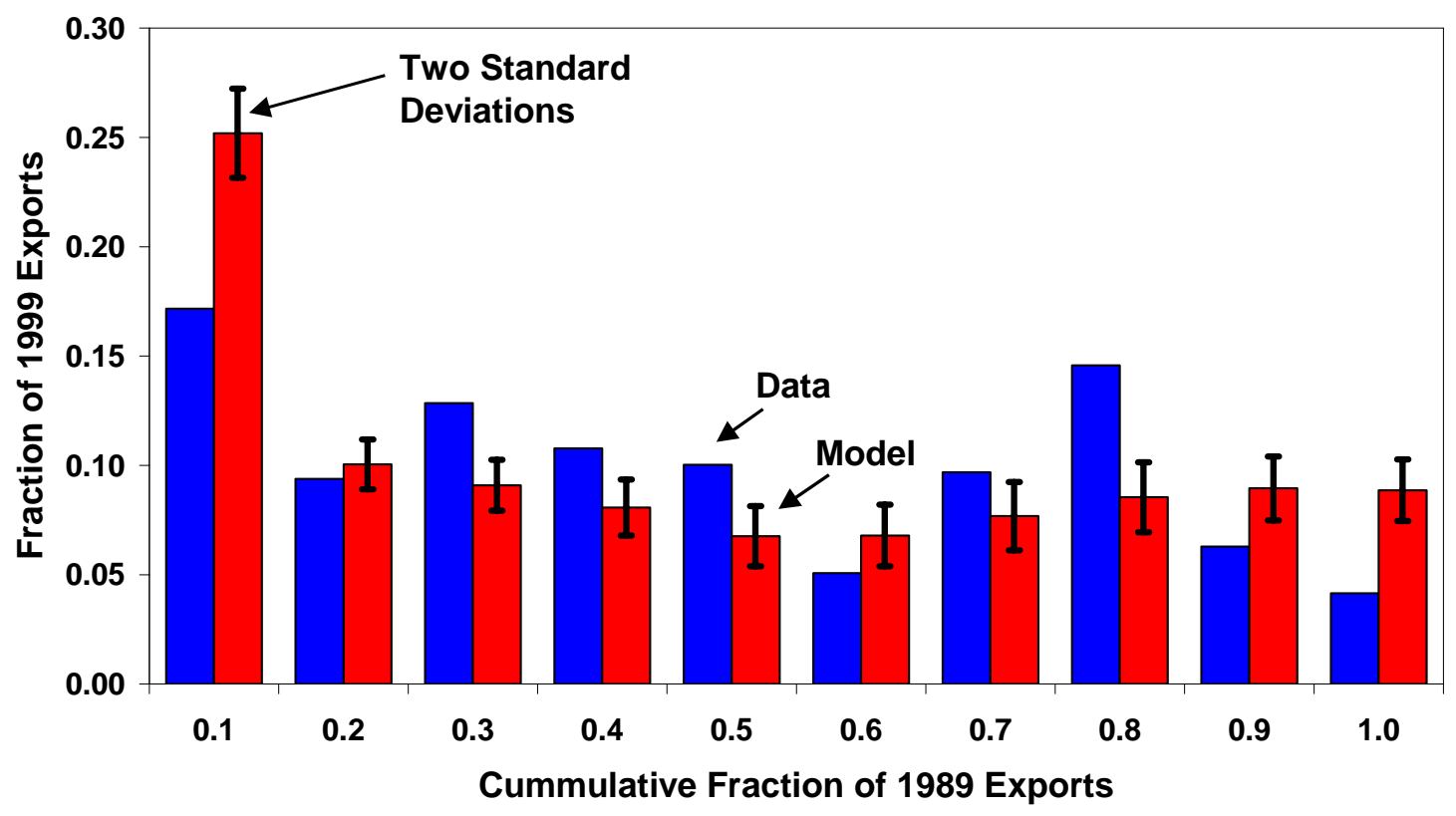

Figure 12

Composition of Exports: Mexico to Canada 1989-1999

By Sets of Categories Based on Export Size

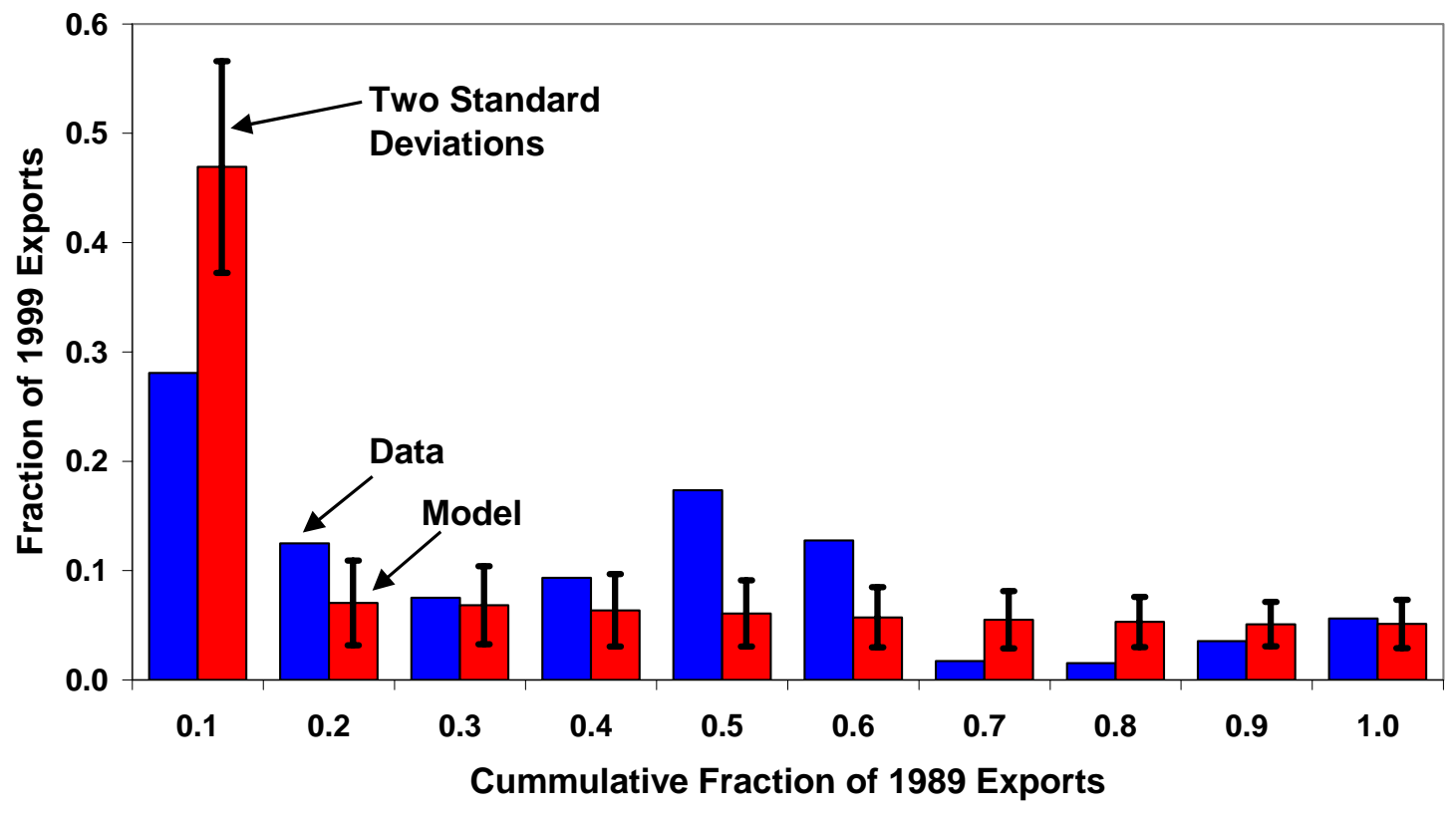


Figure 13

Composition of Exports: Mexico to U.S. 1989-1999

By Sets of Categories Based on Export Size

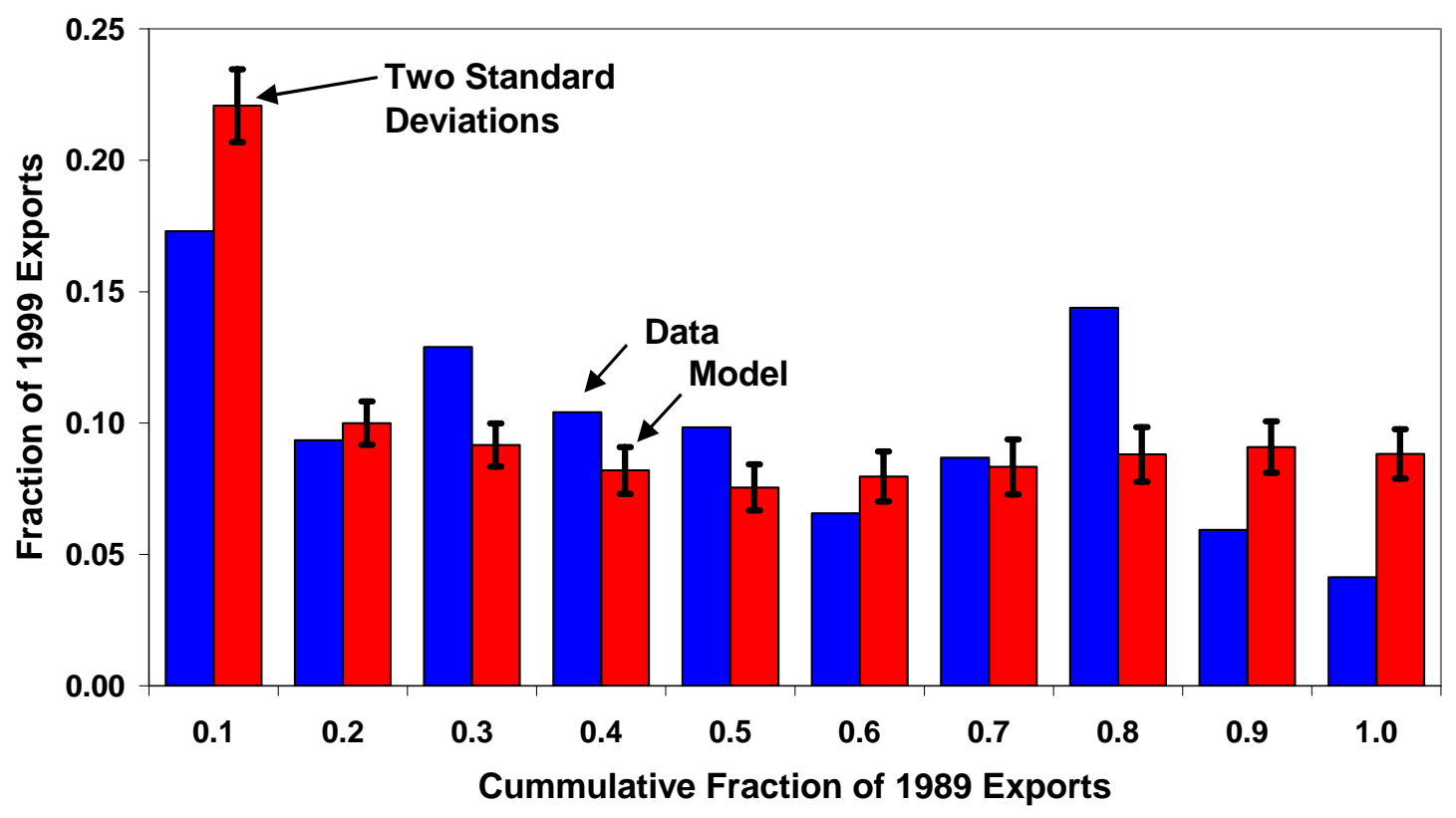

Figure 14

Composition of Exports: Mexico to Canada 1989-1999

By Sets of Categories Based on Export Size

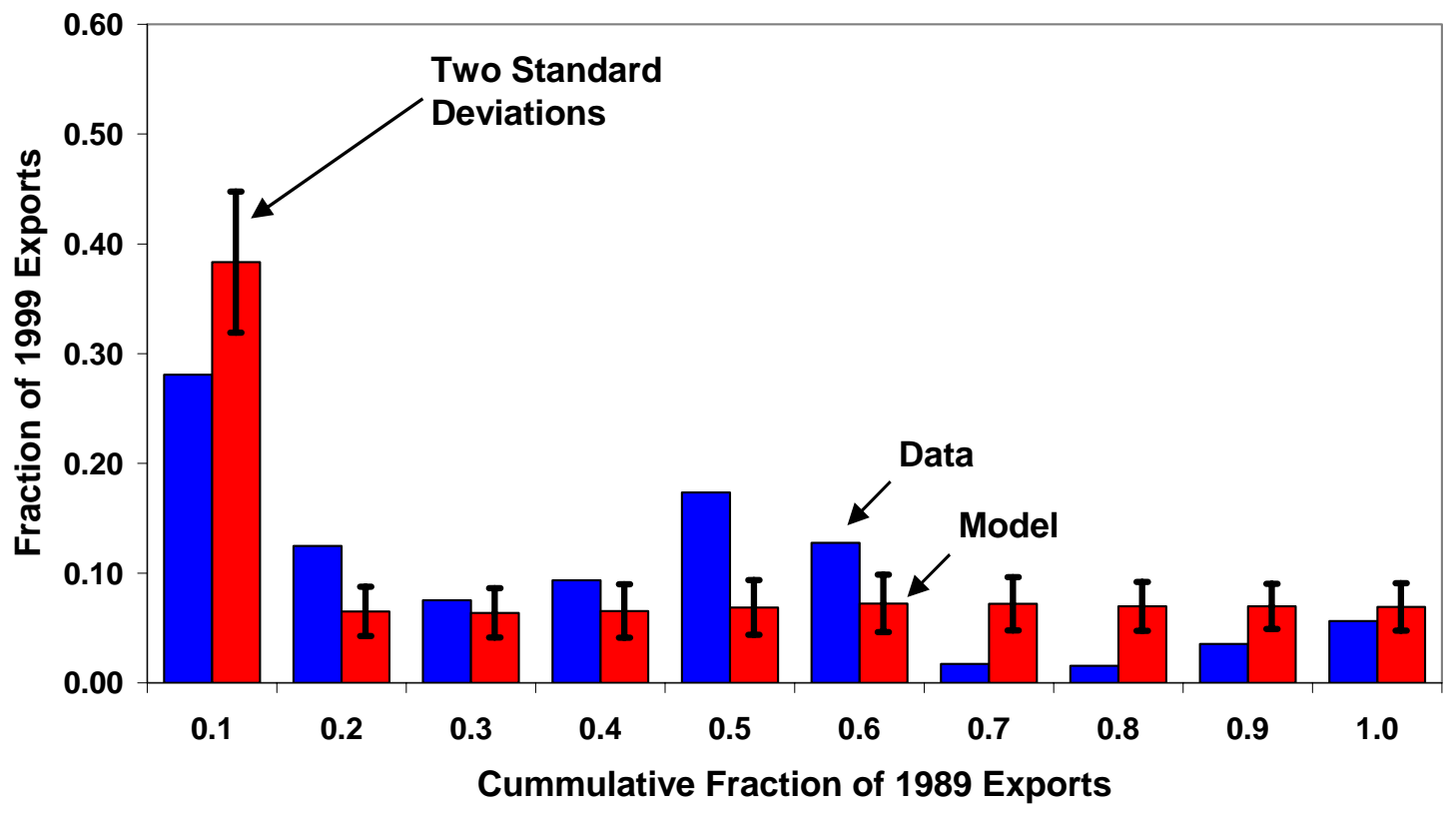


Figure 15

Industry Size Measured by Trade Volume and Gross Output

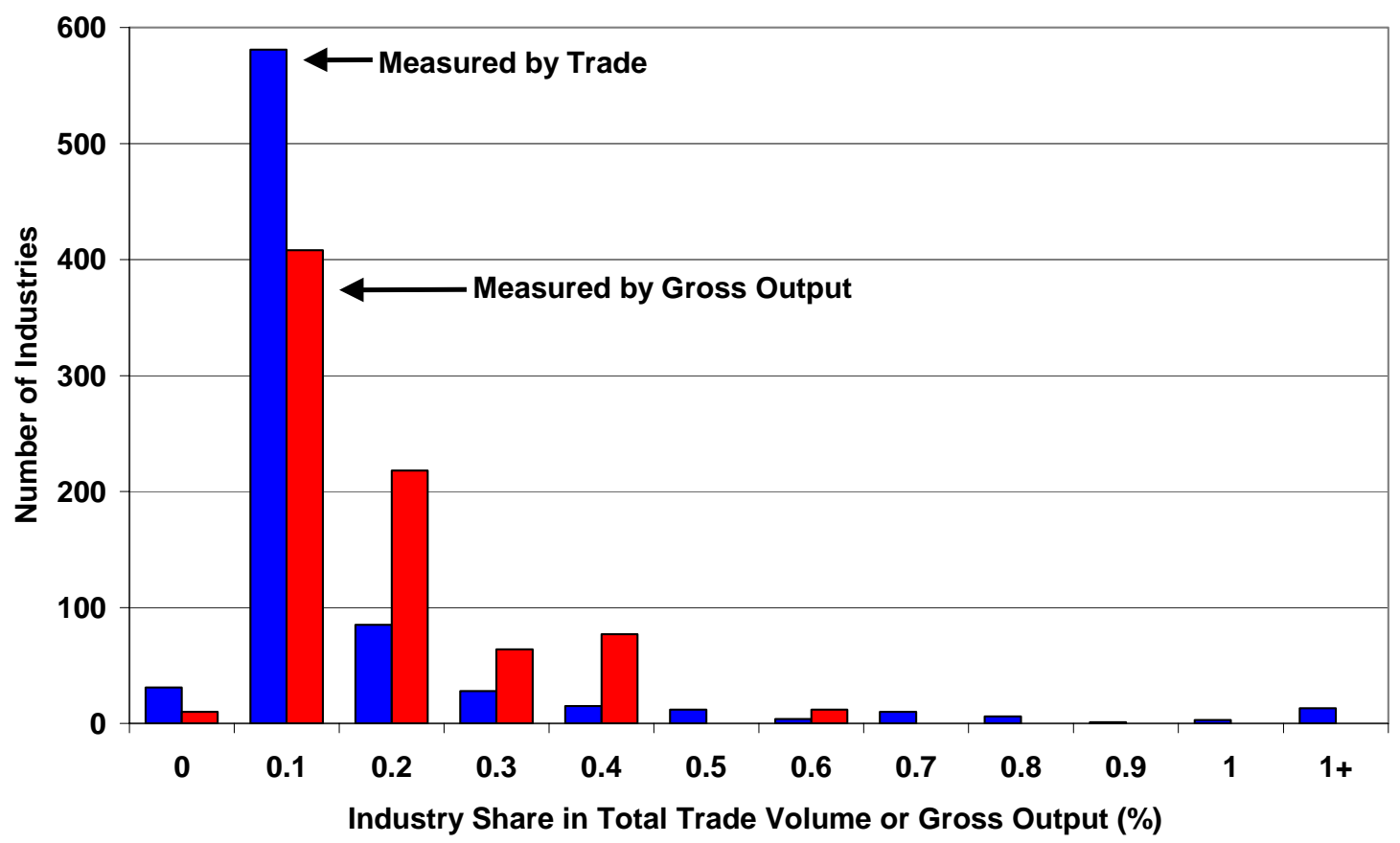

Figure 16

Composition of Exports: Mexico to U.S. 1989-1999

By Sets of Categories Based on Export and Production Size

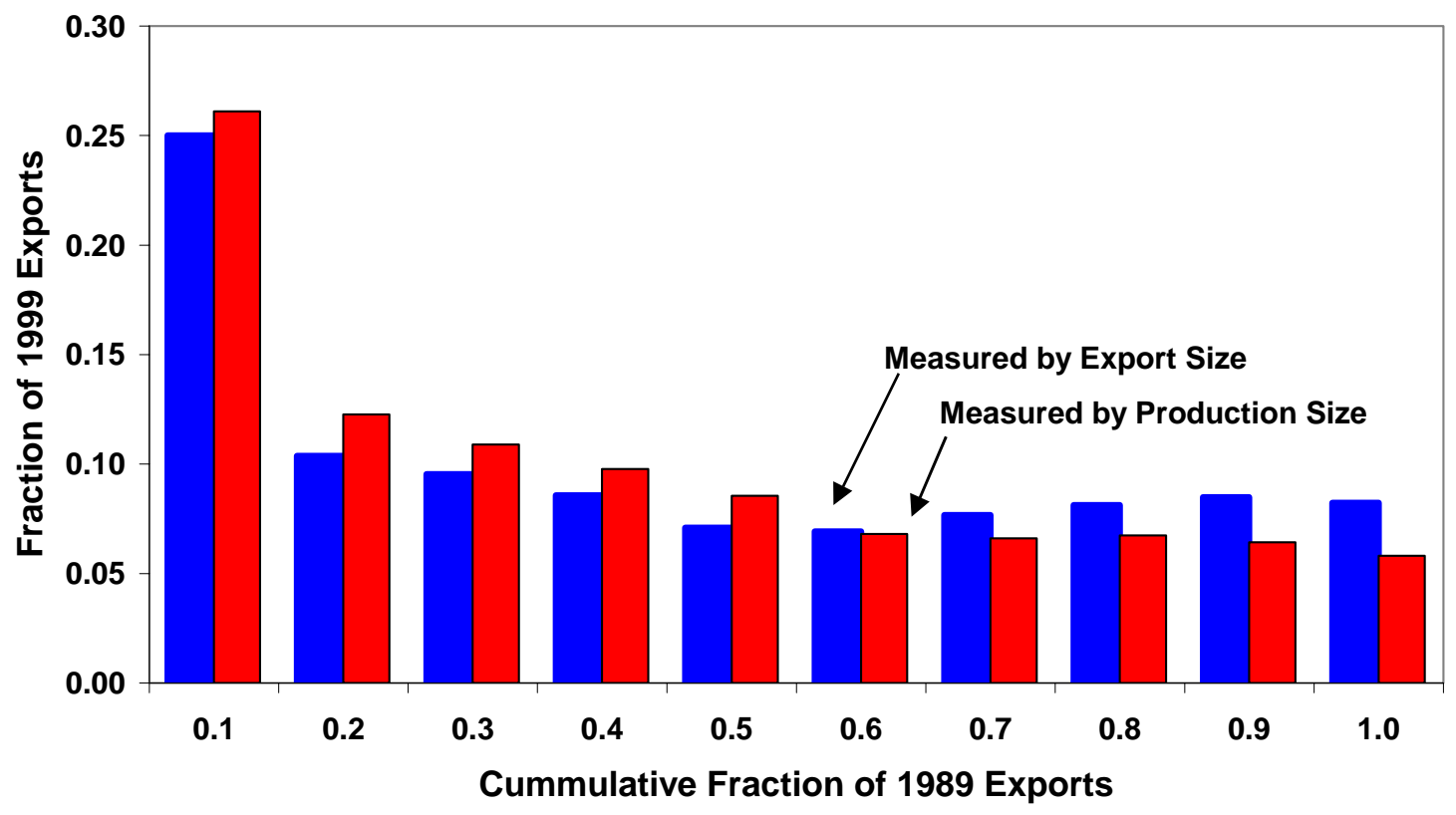

